\title{
La capacidad económica en el impuesto de renta. Análisis con enfoque de género y ponderación de principios relacionados
}

\section{The economic capacity in the income tax analysis with gender. Approach and weighting related principles}

\section{Capacidade econômica na análise do imposto de renda com abordagem de gênero e pesos princípios relacionados}

\author{
Liliana Patricia González BeCERra ${ }^{1}$
}

Resumen

El trabajo hace un análisis desde la óptica del género del actual sistema, en específico a los aspectos relacionados con la capacidad económica de las personas naturales para determinar si algunas condiciones cuantificables en que existen diferencias entre hombres y mujeres crean consecuencias tributarias que no han sido tenidas en cuenta al momento de la configuración del impuesto sobre la renta, tema hasta ahora poco tratado en nuestro país.

Ante esto, mediante un ejercicio de ponderación se estableció cuál de los principios en conflicto (equidad vs. generalidad) prevalecería ante la realidad de las normas constitucionales.

${ }^{1}$ Abogada de la Universidad Libre, Especialista en Derecho procesal de la U. Rosario y Pedagogía de Derechos Humanos de la U.P.T.C.Correo-e: lilianagon1 @ hotmail.com DOI: https://doi.org/10.18601/16926722.n15.05 
Palabras clave: Capacidad económica, Ingresos, Patrimonio, Consumo humano, Análisis con enfoque de género, Generalidad del tributo, Equidad horizontal, Ponderación de principios constitucionales del Derecho tributario

\section{Abstract}

The work makes an analysis from the perspective of the gender of the current system specifically to aspects related to the economic capacity of natural persons to determine if some quantifiable conditions in which there are differences between men and women, create tax consequences that have not been had in mind at the time of the configuration of the income tax, subject until now little treated in our country. Given this, by means of a weighting exercise it was established which of the principles in conflict (equity vs. generality) would prevail before the reality of constitutional norms.

Keywords: Economy capacity, incomes, patrimony, consumption, analysis with a gender approach, generality of the tax, horizontal equity, weighting of constitutional principles of tax law.

\section{Resumo}

O trabalho faz uma análise da perspectiva do gênero do atual sistema especificamente para aspectos relacionados à capacidade econômica das pessoas físicas para determinar se algumas condições quantificáveis em que existem diferenças entre homens e mulheres, criam conseqüências tributárias que não foram em mente no momento da configuração do imposto de renda, assunto até agora pouco tratado em nosso país. Diante disso, por meio de um exercício de ponderação, foi estabelecido qual dos princípios em conflito (equidade versus generalidade) prevaleceria diante da realidade das normas constitucionais.

Palavras chaves: Capacidade econômica, renda, patrimônio, consumo humano, análise com enfoque de gênero, tributação geral, equidade horizontal, ponderação dos princípios constitucionais do direito tributário.

\section{Introducción}

Se parte de la teoría que sostiene que un sistema tributario debe obedecer a principios básicos, como son equidad y justicia, entendidos como la correspondencia entre la obligación tributaria y la realidad de sus usuarios, la generalidad entendida desde la óptica del deber de contribución con los fines del Estado (Artículo 95 numeral 9 de la Constitución Política) que no desconoce ni la equidad, ni la justicia y por el último, el principio de progresividad, que también al ser examinado tiende a consultar la capacidad económica para establecer la exigencia tributaria.

Se consideró adecuado realizar un análisis desde la óptica del género al actual sistema, en específico a los aspectos relacionados con la capacidad económica de las personas naturales, para determinar si algunas condiciones cuantificables en que existen diferencias entre hombres y mujeres, crean consecuencias tributarias que no han sido tenidas en cuenta al momento de su configuración, tema hasta ahora poco tratado en nuestro país. 
A la fecha de elaboración del presente artículo, pueden encontrarse algunos escritos investigativos relacionados con aspectos muy importantes, como la brecha salarial, el llamado impuesto "rosa", la pobreza, en fin, temas muy específicos, cuyas conclusiones o algunas consideraciones nutren este texto, pero no existe trabajo alguno que busque integrarlos y analizarlos en conjunto; por eso es valioso y muy diciente el estudio realizado, que parte de la capacidad económica, tomando sus tres indicadores: ingresos, patrimonio y consumo. Y concluye con la identificación de los principios constitucionales del sistema tributario que deben orientar la inclinación del Derecho tributario en tal situación y, a través de un ejercicio de ponderación, se determina cuál de los dos principios debe primar.

\section{La capacidad económica en el impuesto de renta en personas naturales}

El impuesto de renta de personas naturales en Colombia, teóricamente, es progresivo. Término que ha sido definido como:

La capacidad del tributo para lograr como fruto de su aplicación una redistribución del ingreso que promueve la equidad... y... la condición técnica que se asocia con la progresividad tributaria es que la tarifa aumente respecto del nivel de ingreso o a cualquier variable que se tome como base gravable (Ávila y Cruz, 2006, p. 8).

En el sistema tributario en general y, por ende, en el impuesto de renta, la carga tributaria necesariamente debe responder a dos fundamentos: el beneficio y la capacidad económica. Así lo planteó el Dr. Piza J. R. en el artículo "Capacidad Económica como principio del sistema tributario", en la publicación realizada en la Revista Derecho Fiscal 1, de la Universidad Externado (2011, p. 62).

La capacidad económica constituye el punto de partida de las obligaciones tributarias progresivas y no cuenta con consagración expresa en la Constitución Política colombiana. Sin embargo, sí se ha entendido jurisprudencial y doctrinariamente como un principio general que, como ya se planteó, debe ser orientador fundamental de la potestad tributaria del legislador.

La relación estrecha que existe entre este principio y el de solidaridad son la base de la redistribución solidaria de cargas y obligaciones, ya que el tributo debe ser adecuado a la posibilidad o capacidad de pago del mismo (capacidad contributiva). En la teoría clásica tributaria no podría el tributo afectar los mínimos vitales (techo) ni la subsistencia del individuo. Adicionalmente, quienes cuentan con mayor posibilidad de pago deben contribuir en mayor medida, comparados con quienes se encuentran en inferiores condiciones.

Entonces, si como lo plantea la doctrina, la capacidad económica es el criterio para realizar la igualdad y la generalidad del tributo y depende de la fuerza económica que tiene un sujeto para generar riqueza, debe ser ese concepto el punto de partida de la política fiscal.

Un sistema fiscal que desconoce que la capacidad económica es fundante, no solo es injusto, sino que es poco eficiente desde el punto de vista económico. Así lo ha dejado 
planteado Masbernat (2010), quien describió el tema de la siguiente forma:

Quienes niegan a la capacidad económica el carácter de principio con contenido y vigencia intrínsecos, lo acusan de vago e impreciso, que no entrega claros criterios para enjuiciar las normas, le otorgan exclusivamente un carácter de "lo razonable" en el juicio de constitucionalidad dentro del principio de igualdad, o con efectos muy restringidos (negativos) en el ámbito jurídico y únicamente como límite al legislador. Desde tal perspectiva, su fin sería político y no jurídico, por cuanto de este principio no sería posible obtener directrices operativas a fin de diseñar el sistema tributario o cada impuesto en particular. Sin embargo, parece más adecuado suponer que los problemas que este principio enfrenta son semejantes al de los demás principios materiales (y, en general, a cualquier principio constitucional), pero no por dicha razón estos carecen de relevancia.

En conclusión, el impuesto de renta de personas naturales, como ya se había planteado, es por naturaleza el impuesto que realiza el principio de progresividad y justicia del sistema tributario desde dos puntos de vista muy importantes:

- Basa la tributación en la capacidad económica: la tarifa se aplica sobre una base que debe cuantificar la realidad económica del sujeto pasivo. Colombia ha dado jurisprudencialmente pasos para desarrollar conceptos relacionados, como el derecho al mínimo vital que se da, siempre y cuando se analicen en forma particular las condiciones físicas básicas e indispensables que le permitan la supervivencia digna y autónoma, constituyendo un limitante para el poder impositivo del Estado.

- Es una herramienta eficiente de redistribución de ingresos: si el sujeto pasivo tributa acorde con sus ingresos y estos dineros recaudados (que pesan dentro del presupuesto general con más del 35\% del total de los ingresos tributarios de nuestro estado para el año 2017) financian los fines del estado, en realidad serían de beneficio público y terminarían contribuyendo a quienes obtienen mayores beneficios sociales por parte del estado; es decir, los más vulnerables, haciendo que los que más tienen apoyen el crecimiento de quienes menos poseen.

Por ende, el impuesto de renta de personas naturales tiene estrecha e importante relación con la capacidad económica, de donde surge la necesidad de estudiar el concepto desde sus componentes para concretizarlo y poder medirlo.

\section{II.Indicadores de la capacidad económica: análisis con enfoque de género}

Con el fin de contar con parámetros claros de cuantificación, se utilizarán los indicadores que determinan con mayor claridad la capacidad económica, denominados por la doctrina, esto es el patrimonio (la riqueza, los bienes poseídos), la renta (utilidades conseguidas con la actividad económica y que para efectos de este análisis vamos a trabajar con el indicador ingresos obtenidos con el ejercicio de la actividad económica y finalmente el consumo. 
De nuevo, se denota la relación existente entre los tres indicadores que permiten medir la capacidad económica con el impuesto de renta, ya que son factores que se encuentran altamente gravados en el sistema tributario colombiano y son los pilares sobre los cuales se determina el impuesto de renta de personas naturales, estableciendo sobre ellos los topes para detentar o no la obligación de declarar. En adelante, el estudio acudirá a cada uno de ellos para analizar con enfoque de género la capacidad económica.

\section{A. Análisis de aspectos comunes a todos los indicadores de la capacidad económica}

De acuerdo con la población proyectada por el Departamento Nacional de Planeación DANE para el 30 de junio de 2017, de los 49.291.609 de colombianos, el 49,31\% son hombres y el $50,62 \%$ son mujeres.

Ahora bien, conforme al único estudio que tiene la DIAN con enfoque de género elaborado por Javier Ávila Mahecha y denominado Diferencias de género en la riqueza, ingresos y renta de personas naturales en Colombia, publicado en febrero de 2016 por dicha entidad, se evidencia que en el 2014 "algo más de dos millones de personas presentaron declaración de renta", lo que quiere decir que los declarantes corresponden "aproximadamente al $10 \%$ de la población ocupada y menos del 5\% de la población total".

Trasladando estos datos al año 2017, el total de declarantes correspondería a cerca de 2.500.000 personas, pretendiendo discriminar ese gran total por género y partiendo del estudio ya mencionado que permitió concluir que "del total de las declaraciones analizadas (1.513.074) el 46\% corresponde a mujeres..." (691), mientras que los hombres declarantes son 822 ... en el promedio nacional 84 mujeres declaran renta por cada 100 hombres que cumplen esta obligación...". Podría decirse, entonces, que cerca de un millón ciento cincuenta mil mujeres serían declarantes de renta por el año 2017.

El dato anterior nos habla de los indicadores planteados, ya que está claro que son declarantes las personas privilegiadas en oportunidades dentro de la sociedad y, de aquellos individuos, hay mayor cantidad de hombres que cumplen con los topes establecidos por el gobierno nacional en relación con las mujeres.

Las conclusiones más importantes del análisis efectuado a nivel nacional por el Dr. Ávila (2016) pueden resumirse en cifras bastante dicientes como las que siguen:

Del total en millones del patrimonio líquido (\$ 623), los hombres poseen el 52,1\% y las mujeres, el 47,8\%. Además, en relación con los ingresos brutos que en general sumaron \$ 269 millones, obtuvieron el 63,56\% los hombres, mientras que las mujeres un $36,43 \%$, tal como puede verse en la tabla 1 .

Tabla 1.

Indicadores por género - año gravable 2014

\begin{tabular}{|l|l|l|}
\hline \multicolumn{1}{|c|}{$\begin{array}{c}\text { Parámetro de } \\
\text { comparación }\end{array}$} & \multicolumn{1}{|c|}{ Hombres } & \multicolumn{1}{c|}{ Mujeres } \\
\hline Activos & 411 millones & 354 millones \\
\hline Ingresos brutos & 171 millones & 98 millones \\
\hline Patrimonio & 325 millones & 298 millones \\
\hline
\end{tabular}

Fuente: Adaptada de Ávila (2016, p. 17).

Los datos varían ligeramente dependiendo la zona del país donde se ubiquen los declarantes. En Boyacá, por ejemplo, donde 
declararon 39.092 personas, el $43 \%$ fueron mujeres y el restante $57 \%$ de declarantes pertenecen al género masculino. Ellos declararon un $52 \%$ del total de patrimonio líquido y las mujeres, un 47,9\% del mismo indicador. En cuanto a los ingresos brutos percibidos de un total de $\$ 247$ millones (ingresos por debajo del promedio general del país), los hombres devengaron el 62,3\% y las mujeres el $37,6 \%$.

Tabla 2.

Indicadores por género en Boyacáaño gravable 2014

\begin{tabular}{|l|c|c|}
\hline \multicolumn{1}{|c|}{$\begin{array}{c}\text { Parámetro de } \\
\text { comparación }\end{array}$} & Hombres & Mujeres \\
\hline Patrimonio líquido & 219 & 202 \\
\hline Ingresos brutos & 154 & 93 \\
\hline
\end{tabular}

Fuente: Adaptada de Ávila (2016, pp. 23 y 24).

\section{Análisis de cada indicador de la capacidad económica}

\section{a. Patrimonio:}

Si se debiera hacer una definición simple del concepto, podría decirse que se denomina patrimonio al conjunto de bienes que pertenecen a una persona natural o jurídica. Entonces, constituyen el patrimonio los bienes y derechos apreciables en dinero.

Para poder detallar el concepto debe acudirse a los escasos datos cuantificados disponibles sobre bienes y derechos, dentro de los que se pueden mencionar:

\section{i. Vivienda propia}

Para el año 2016, según el Ministerio de Vivienda, Ciudad y Territorio, las mujeres representaron el $70 \%$ de los propietarios de vivienda en Colombia, principalmente de vivienda de interés social, adquiriendo ellas los compromisos de pago y la obligación crediticia. Esta cifra es positiva porque se relaciona con la calidad de vida de las mujeres y sus familias, pero también implica que la mayor parte de los ingresos de las mujeres se van a ver comprometidos con los impuestos que recaen sobre la propiedad, además de las obligaciones adquiridas para el pago.

\section{ii. Depósitos en el sector financiero}

Aunque se han desarrollado estudios de inclusión de colombianos en el sistema financiero, pocos de ellos tienen enfoque de género con respecto a los activos, principalmente. Sin embargo, se cuenta con la siguiente información: del total de la población colombiana para el año 2018 -primer trimestre-, el 80,1\% cuentan con, por lo menos, un servicio en el sector financiero. De ese gran total de usuarios del sistema, las mujeres poseen el $56,1 \%$ de las cuentas de depósitos, mientras que los hombres el 65,2\% (Arango, Suárez y Garrido, 2017).

Situación que se hace más diciente si se tiene en cuenta que son las mujeres quienes son las mayores usuarias del sistema. De acuerdo con el Reporte trimestral de Inclusión Financiera de marzo de 2018, se informa que el 83,6\% de las mujeres se encuentran utilizando el sistema financiero, frente al 76,5\% de los hombres que lo hacen. Lo cual permite pensar que la diferencia se podría dar en la participación de las mujeres en los productos relacionados con créditos $\mathrm{y}$, efectivamente, esa ha sido la tendencia: acudir al endeudamiento principalmente para poner en marcha proyectos de emprendimiento y creación de nuevos negocios. 


\section{iii. Emprendimiento}

Las cifras sobre emprendimiento o propiedad de empresa en Colombia por género son bastante escasas: tan solo se cuenta con el estudio más reciente realizado por Global Entrepreneurship Monitor (GEM), (2017). Este análisis indica que de los empresarios que el estudio denomina establecidos, por cada mujer empresaria hay dos hombres; es decir que la proporción de participación femenina es del $50 \%$ en los empresarios debidamente constituidos en nuestro país.

En 2017, Portafolio publicó un análisis efectuado a partir del ya mencionado estudio empresarial, según el cual las mujeres empresarias han crecido en Colombia en los últimos años debido a la forma como utilizan sus ingresos:

... las mujeres de los países emergentes reinvierten 90 centavos de dólar por cada dólar adicional de ingreso en el bienestar de su familia, con lo que además impulsa el desarrollo de la comunidad y la sociedad en general. Los hombres apenas invierten en estos aspectos entre un $30 \mathrm{y}$ un $40 \%$. Por lo mismo, aumentar los ingresos de las mujeres resulta, en el agregado final, más beneficioso para la economía en general...

Información que se complementa con lo aportado por Fenalco para el mismo artículo mencionado: "el $21 \%$ de los negocios en el país corresponden a tiendas de barrio. De las cuales el $56 \%$ de las tiendas pertenecen a mujeres".

En conclusión, aunque las mujeres poseen en mayor medida la propiedad de vivienda en el país, sus activos en depósitos son infe- riores a los de los hombres, su participación en el mercado financiero es principalmente dada al crédito y son dueñas de tan solo el $50 \%$ de las empresas del país. Además, el negocio en el que más participan es el de las tiendas de barrio.

\section{b. Renta - Ingresos}

Un ingreso implica un incremento de los recursos económicos y por ende del patrimonio, ya que genera el aumento del valor de los activos o la disminución de un pasivo.

El análisis que se emprende contempla dos realidades:

- La existencia de personas de ambos sexos que cuentan con ingresos derivados del desarrollo de determinada actividad económica, ya sea como independientes o como asalariados.

- La población que no cuenta con ingresos propios, sino que depende de un perceptor de ingresos.

\section{i. Aspectos relacionados con población desocupada y que no percibe ingresos propios}

Para iniciar el análisis del indicador ingresos se tomará en primer lugar el numeral b de las realidades enunciadas en el párrafo anterior, por cuanto constituye un solo aspecto: la población laboralmente desocupada.

$\mathrm{Al}$ respecto se cuenta con estudios del DANE (2017), en los cuales se determinó que, de la población económicamente activa y en edad de trabajar, constituida por las personas de 12 y más años en la parte urbana y de 10 años y más en la parte rural, que están traba- 
jando o buscando trabajo, el $56,7 \%$ corresponde a hombres y el 43,3\% corresponde a mujeres. Notándose que el género femenino está menos presente en el mercado laboral, bien sea como independientes o asalariados. Indicador que se ha venido presentando de forma similar históricamente.

Tabla 3.

Porcentaje de mujeres y hombres en relación con la ocupación económica 2017

\begin{tabular}{|l|c|c|}
\hline \multicolumn{1}{|c|}{ Indicador } & Hombres & Mujeres \\
\hline Población ocupada & $75,10 \%$ & $59,60 \%$ \\
\hline Población desocupada & $44 \%$ & $56 \%$ \\
\hline
\end{tabular}

Fuente: Adaptada del Boletín Técnico. Mercado laboral por sexo trimestre móvil marzo - mayo 2017 DANE. Bogotá

Figura 1.

Tasas de participación laboral. Histórico

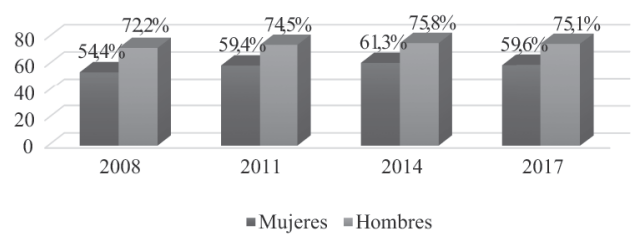

Fuente: Tenjo y Bernat (2017, p. 2).

A pesar de ser mayoría poblacional, la participación de las mujeres en el mercado laboral es menor, presentando una mayor tasa de desocupación. Cifras que van en aumento para el 2018.

Tabla 4.

Porcentajes de mujeres y hombres en relación con la ocupación económica 2018

\begin{tabular}{|l|l|l|}
\hline \multicolumn{1}{|c|}{ Indicador } & Hombres & Mujeres \\
\hline Desempleo & $7,4 \%$ & $12,4 \%$ \\
\hline participación & $74,8 \%$ & $53,6 \%$ \\
\hline Población ocupada & $69,3 \%$ & $46,9 \%$ \\
\hline Población desocupada & $25,2 \%$ & $46,4 \%$ \\
\hline
\end{tabular}

Fuente: Porcentajes de mujeres y hombres en relación con la ocupación económica 2.018, adaptada por la autora del Boletín técnico Gran Encuesta Integrada de Hogares
(GEIH) junio 2018, Principales indicadores del mercado laboral junio de 2018.

De acuerdo con las cifras de los Informes especiales de mercado laboral del DANE (2018), las actividades en que se registra mayor participación masculina son:

Trabajador por cuenta propia con $45,1 \%$; Comercio, hoteles y restaurantes $(22,6 \%)$, y Agricultura, ganadería, caza, silvicultura y pesca $(22,4 \%)$.

Para el total nacional en el trimestre móvil mayo-julio de 2018, la posición ocupacional que registró la mayor participación para las mujeres fue Trabajador por cuenta propia con $41,1 \%$, Seguido por Comercio, hoteles y restaurantes $(32,8 \%)$, y Servicios comunales, sociales y personales $(32,4 \%)$.

Figura 2.

Tasas de desempleo. Histórico

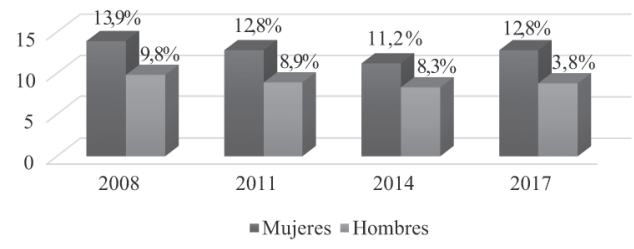

Fuente: Tenjo y Bernat (2017,p. 2).

Otro análisis relevante con relación a la inactividad consiste en saber que el 25,2\% de la población masculina en edad de trabajar era económicamente inactiva. De esa población, el 58,4\% de la población masculina económicamente inactiva se dedicó principalmente a estudiar, mientras que del $46,4 \%$ de la población femenina en edad de trabajar, que era económicamente inactiva, el 59,4\% se dedicó principalmente a oficios del hogar. 
La percepción de ingresos constituye uno de los topes creados por el legislador para determinar los contribuyentes de renta en las personas naturales. Es decir, se presume que quienes estén obligados a declarar renta perciben ingresos propios. Se podría decir también que el escenario de quienes no tienen ingresos propios se sale de los análisis de esta investigación. Sin embargo, como lo pretendido es mostrar la disimilitud en cuanto a la capacidad económica entre hombres y mujeres, vale el análisis de la realidad planteada.

El devengar ingresos propios confiere autonomía y posibilidad real de decisión sobre la administración del mismo. Nadie dispone libremente del dinero que le pertenece a otra persona, lo que crea mayor dependencia en la toma de decisiones económicas. La CEPAL, en su observatorio para la equidad de género de América latina y el Caribe, publicó en el año 2016 un estudio cuyo resultado puede verse en la figura 2. Para el caso de Colombia, el $26,4 \%$ de las mujeres mayores de 15 años carecen de ingresos propios y dependen de personas perceptoras, mientras que el $10,3 \%$ de hombres viven esa realidad.

\section{ii. Aspectos relacionados con la población ocupada y que devenga ingresos}

Para continuar el desarrollo del estudio planteado se iniciará lo pertinente al literal a, que corresponde a la población que devenga ingresos producto del desarrollo de una actividad laboral, donde se abordarán varios aspectos:

\section{- Brecha salarial}

ONU Mujeres (2013) publicó en su portal un análisis relacionado con el empoderamiento económico, según el cual "en la mayoría de los países, las mujeres en promedio ganan sólo entre el 60 y el 75 por ciento del salario de los hombres".

Esta realidad poco aceptada tiene detrás varios factores determinantes: el demostra-

Figura 3.

Población sin ingresos propios, por sexo

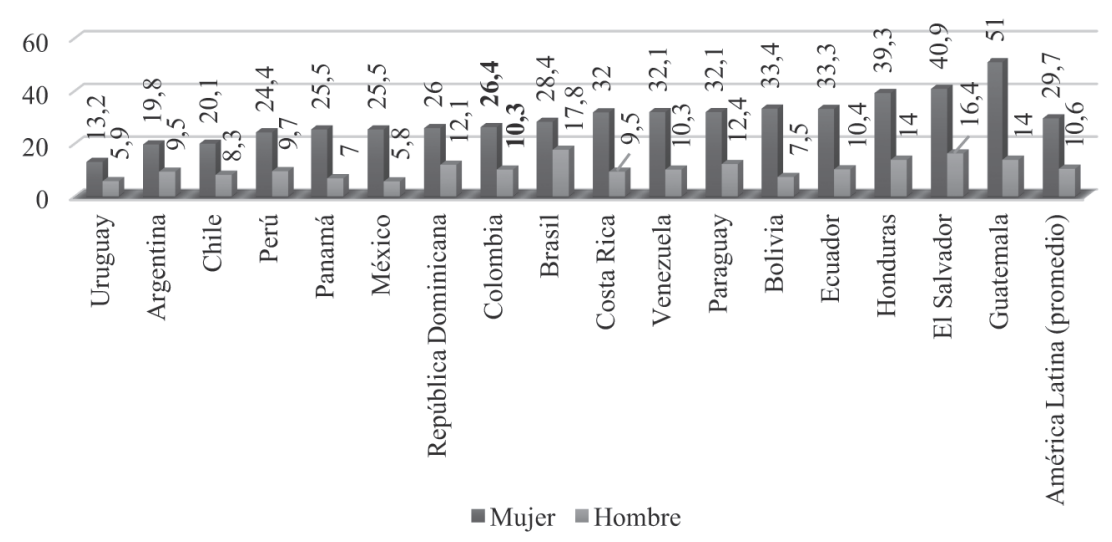

Fuente: CEPAL (2016). 
ble empleo de mujeres en economía de cuidado que trae consigo la dedicación horaria inferior a trabajos remunerados, el tipo de actividades económicas desempeñadas por ellas que son, generalmente, menos generadores de riqueza, la vinculación al sector informal de la economía y la imposibilidad de movilidad laboral de las mujeres en relación con los hombres.

\section{Brecha salarial}

¿Existe una brecha salarial entre hombres y mujeres? La CEPAL (2016) realizó un análisis pertinente al tema, que aporta un elemento más a la construcción de las bases de la ya tantas veces mencionada desigualdad salarial y tiene que ver con los empleos en donde se ocupan unos y otras. Por un lado, los hombres tienen el 10,1\% de participación laboral en el sector de alta productividad (ubicado más cerca de la vanguardia tecnológica, con mayor nivel educativo, mejores condiciones laborales y condiciones más estables de permanencia), siendo características de este sector la actividad financiera, electricidad y minería; en donde solo el $10,5 \%$ de las mujeres participa. Por otro lado, las mujeres ocupan su capacidad laboral en un $72,5 \%$ y los hombres en un $56,5 \%$, en sectores de baja productividad (menores ingresos, menor nivel educativo, inestabilidad, limitada cobertura de seguridad social y ausencia de contratos de trabajo).

A manera de ejemplo, tenemos empleos en agricultura, comercio y servicios. En la media se encuentra el sector de productividad media: construcción, manufactura y transporte, con una participación masculina de $33,4 \%$ ante un $17 \%$ de la de las mujeres.

En ese mismo sentido, de acuerdo con la Encuesta Nacional de Salud y Demografía del Ministerio de salud del año 2015, las mujeres acceden en mayor medida a trabajos sin remuneración que los hombres. Igualmente, son ellas las que reciben más salarios en especie o mixtos que los hombres. Esto, tal vez, debido a la participación de las personas de género femenino en la economía de cuidado y también al tipo de trabajos que desempeñan unos y otros.

En conclusión: la brecha salarial está dada en general por la diferencia de empleos que detentan, la calidad de empresas, industrias o negocios en que se desarrollan y el tipo de actividad económica en que participan.

\section{iii. Relación entre educación e ingreso}

De nuevo con las cifras del DANE (2017), se puede demostrar que el ingreso en nuestro país tiene relación con la educación, ya que el promedio de toda la fuerza laboral es de casi 11 años de educación. Las personas que perciben ingresos como consecuencia de una relación laboral tienen dos años de educación más que los independientes, "lo cual puede indicar que ser independientes es una opción que les queda a algunas personas con bajos niveles educativos". Las mujeres asalariadas tienen un año más de educación que los hombres asalariados; empero, tratándose de independientes, las mujeres tienen menos educación que los hombres, como lo demuestran los siguientes gráficos. 
Figura 4. Años promedio de educación asalariados

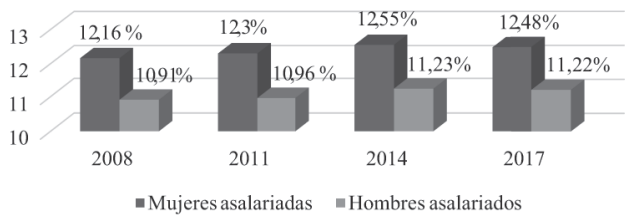

Fuente: Tenjo y Bernat (2017, p. 3).

\section{Figura 5}

\section{Años promedio de educación independientes}

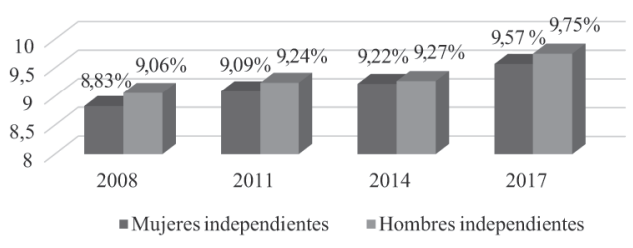

Fuente: Tenjo y Bernat (2017, p. 3).

\section{iv. Fenómenos llamados Techo de Cristal y} Piso pegajoso

Un aspecto cultural muy importante, que tiene estrecha relación con la brecha salarial, son dos fenómenos sociales conocidos en el mundo como Techo de cristal y Piso pegajoso. Son una limitante para el desarrollo profesional de las mujeres y podrían definirse como obstáculos invisibles que la sociedad, a través de sus creencias culturales, ha estructurado sobre lo femenino y lo masculino; es decir, aquello que se relaciona con los roles de género.

Tradicionalmente, las mujeres se asocian con el cuidado y los hombres, con la fuerza. Así mismo, las actividades de cuidado, se cree, tienen poca importancia económica, mientras que aquellas que requieren fuerza o resistencia son más valoradas.

En primer lugar, el piso o suelo pegajoso es el límite inferior que mantiene a las mu- jeres adheridas a sus labores de cuidado, que, como se demostrará más adelante, se encuentran poco o nada remuneradas. Las mujeres culturalmente se sienten responsables de la familia, los hijos y el hogar. Afectiva y emocionalmente se sienten ligadas a sus roles de madre, hija y esposa. Labores bastante importantes que le impiden a la mujer ubicarse laboralmente o reubicarse para conseguir mejores condiciones profesionales; es la barrera que imposibilita también la formación, ya que en la mayoría de los casos implica salir del hogar e "incumplir" deberes domésticos.

También constituye piso resbaloso la feminización de algunas actividades económicas por las que se generan ingresos menores, condiciones laborales inferiores y mayor dificultad de ascenso. A manera de ejemplo se citan la labor secretarial y la de enfermería.

Por otro lado, el Techo de cristal es la barrera superior invisible en la carrera laboral de las mujeres que les impide ascender. Los estereotipos que conforman este techo están relacionados con el manejo del poder, la responsabilidad económica y social, la autoridad, el tiempo y el compromiso familiar. Estos provocan que las mujeres sean poco elegibles para cargos de dirección y poder, en la mayoría de los casos interiorizando el rol de tal forma que el techo es su propia decisión. Entonces, el Techo de cristal mantiene a las mujeres trabajadoras en cargos medios, en donde se sienten más cómodas al no tener que tomar decisiones y ejercer poder; sobre todo por encima de sus pares masculinos y en donde sienten que puede cumplir con las labores de cuidado que la naturaleza les exige. 
Estos límites relacionados con estereotipos de género serán superados en la medida en que exista equidad de género que permita, tanto a hombres como a mujeres, repartirse las labores domésticas y las vastas responsabilidades de familia sin importar el género, y el apoyo mutuo para el crecimiento tanto profesional, como económico y, además, sin perder la esencia de familia.

\section{v. Economía de cuidado}

Gómez E. (2008) explica en su estudio como "el trabajo no remunerado es la forma predominante de trabajo en la producción de subsistencia". El llamado trabajo doméstico, que incluye cuidados por parte de una persona a otros, las labores de administración y mantenimiento del hogar y el voluntariado en la comunidad, es conocido como Economía de Cuidado y constituye un indicador macroeconómico importante y necesario de cuantificar. Este sector de la economía aporta al bienestar de la comunidad a través del desarrollo de capacidades humanas, lo que conlleva un crecimiento económico a largo plazo. Adicionalmente, cabe resaltar que se trata de una cifra irrisoria, ya que podría representar más de la mitad del Producto Interno Bruto (PIB), debido a la cantidad de horas empleadas en este.

Estas tareas, que culturalmente han sido atribuidas a las mujeres, sí tienen una implicación económica, ya que son trabajo y aunque las mujeres participan cada vez más en el trabajo remunerado, está demostrado que no se ha dado paralelamente la redistribución significativa del trabajo no remunerado. Por lo tanto, las mujeres continúan siendo las responsables de la mayor parte del trabajo que no percibe remuneración.
Por esto, se creó una Cuenta Satélite de Economía de Cuidado (CSEC), que pretende hacer la medición de la relación entre la economía del cuidado y el resto de la economía, para, así, obtener resultados cuantificables que permitan incluir la economía del cuidado en las Cuentas Nacionales de nuestro país. Lo anterior, en cumplimiento de la Ley 1413 de 2010, "Por medio de la cual se regula la inclusión de la economía del cuidado en el sistema de cuentas nacionales con el objeto de medir la contribución de la mujer al desarrollo económico y social del país y como herramienta fundamental para la definición e implementación de políticas públicas”.

Esta labor de cuidado conllevó que el tiempo total de trabajo para mujeres fuera, para los años 2016- 2017, de 13 horas con 24 minutos y para los hombres, de 11 horas con 16 minutos.

De este tiempo empleado en trabajar, tan solo se recibe remuneración por las labores que forman parte del sistema de cuentas de la nación, que para las mujeres constó de 7 horas con 35 minutos. En los hombres, el tiempo diario promedio dedicado al trabajo comprendido fue de 9 horas con 14 minutos. Este tiempo utilizado para el desarrollo de las actividades ya mencionadas y la falta de remuneración en cada una de ellas incide directamente en el ingreso de las mujeres.

\section{d. Consumo}

Analizadas las dos primeras variables que son indicadores de la capacidad económica solo resta, con los incipientes datos que pueden obtenerse, realizar lo propio con lo que respecta al consumo. 
Si se entiende el consumo como la tendencia a adquirir los bienes y servicios que satisfacen las necesidades presentes o futuras de las personas y sin tener en cuenta los aspectos culturales que este indicador conlleva, ya que serán analizados en otro momento de esta investigación, se puede realizar el siguiente análisis:

De acuerdo con las cifras del DANE, los colombianos gastan el 29,5\% del presupuesto familiar para la compra de alimentos, otro $29,4 \%$ para vivienda, donde se incluye el pago de arriendos, servicios de agua, energía, gas y teléfono; la compra de muebles y productos de limpieza; el 13,49\% para transporte, el 7,31\% para vestuario, el 4,83\% para educación, el 3,98\% para salud y el 3,6\% para cultura, diversión y esparcimiento.

\section{i. Canasta familiar}

Los gastos anteriormente relacionados, a grandes rasgos, se denominan canasta familiar; dentro de la que existe un rubro denominado otros, en el cual las familias usan el $7,89 \%$ del presupuesto; allí están incluidas las bebidas, el tabaco y los artículos de aseo personal.

El cuestionamiento, entonces, sería ¿quién adquiere esos bienes y servicios? La revista Dinero (2013), en abril, realizó un análisis en el que concluye que las mujeres controlarían 2/3 del consumo para la próxima década. Teniendo presente que la relevancia de la mujer en la economía colombiana es tan grande que, según Camilo Herrera, presidente de Raddar (colectivo experto en consumo y

Figura 6.

\section{Conformación canasta familiar en Colombia}

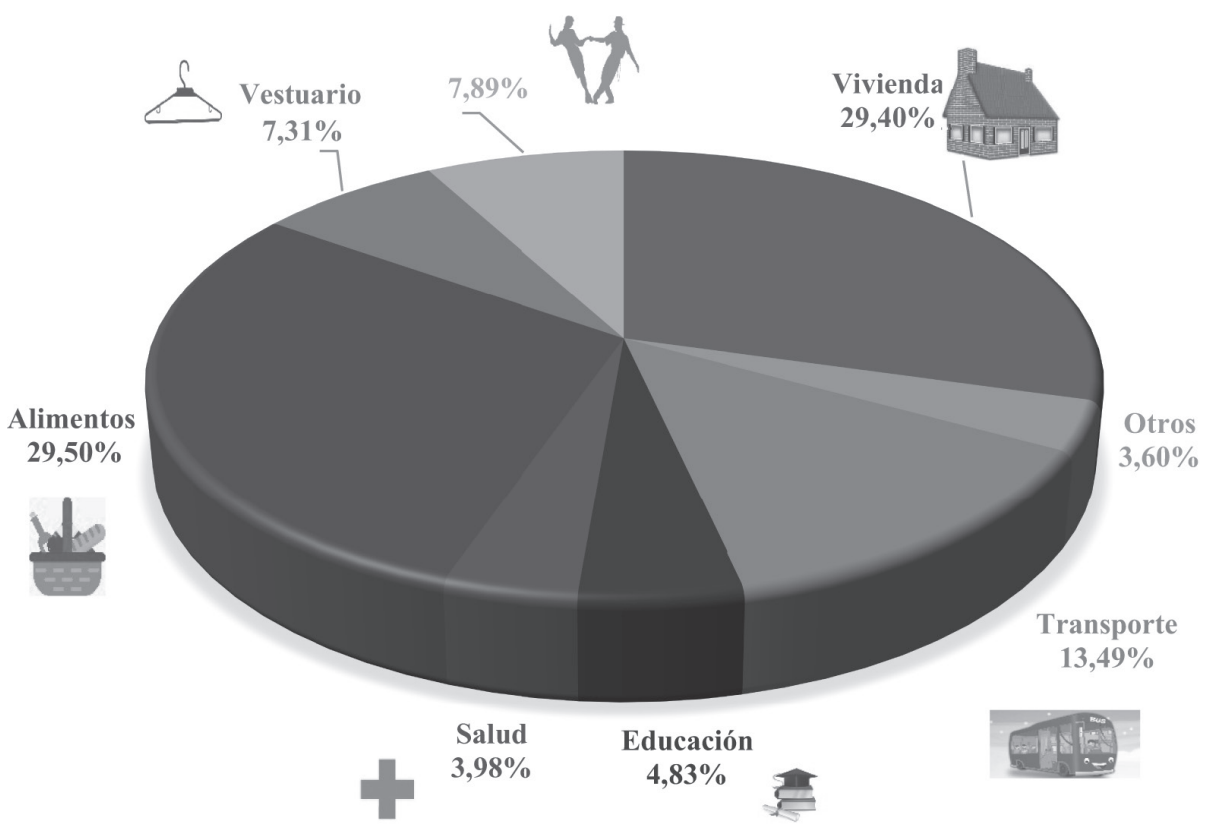

Fuente: DANE (2018). 
compras), ellas manejan el $70 \%$ del gasto mensual de los hogares en el país; una cifra que asciende a cerca de 272,2 billones de pesos cada año.

Las mujeres poseen la decisión o, mejor, la necesidad de compra de 2 de cada 3 productos en el mercado formal colombiano. Productos que se encuentran relacionados con el Hogar y la Canasta familiar. Así reflejó Camilo Herrera esa realidad: "En Colombia, la decisión de comprar bienes durables (como por ejemplo un carro) la toman los hombres, pero cuando se trata de compras frecuentes (como de la canasta familiar), quedan en manos de las mujeres".

A su vez, y en concordancia con el análisis mencionado, Portafolio en el año 2018 publicó un artículo que concluye que "el $83 \%$ de las compras que se realizan en América Latina a través de internet tienen influencia femenina, ya que son las mujeres las encargadas de temas del hogar y artículos para la familia". Lo anterior cobra fuerza al compararse con el estudio efectuado por Raddar, según el cual las mujeres hicieron compras por $\$ 156$ billones y la categoría donde más gasto hubo en el hogar e individual fueron alimentos: "De cada 10 pesos, 7 fueron en compras para el hogar y 3 pesos fueron de compras para ellas", aseguró la firma en el respectivo informe.

En Colombia, la ENDS (2015), luego de demostrar que más del $60 \%$ de las mujeres que reciben dinero en remuneración por su trabajo deciden solas como gastarlo, evidenció que su aporte a los gastos de sus hogares es muy importante y corresponde a un 50,8\%, discriminado de la siguiente forma: un 4,5\% de las mujeres cubre todos los gastos de su hogar y un 46,3\% cubre la mitad o más de la mitad. Ahora bien, estando relacionado el aporte con el número de hijos, ocurre que al aumentar el número de hijos desciende la proporción de las que no aportan nada al gasto del hogar (de 9,2\% a 2,4\%), decreciente la proporción de las que aporta la mitad o más de la mitad (de $51,7 \%$ a $44,7 \%$ ) y muy creciente la proporción de las que aportan todo el gasto del hogar (de $3,2 \%$ a $11 \%$ ) debido a que sus ingresos se ven afectados por la necesidad de abandonar sus hogares y dedicarse a cuidar de los hijos.

Por su parte, las proporciones de hombres que no aportan nada $(0,1 \%)$, casi nada $(0,8 \%)$ o hacen aportes inferiores de la mitad del gasto del hogar $(4,3 \%)$ e incluso los que aportan la mitad $(24,5 \%)$, son mucho menores que en el caso de las mujeres. Mientras que las proporciones de los que aportan más de la mitad $(31,2 \%)$ o todo el gasto del hogar $(39,1 \%)$, son muy superiores al caso de las mujeres.

De lo hasta acá propuesto, puede concluirse que la relación ingreso-gasto tiene diferencia de acuerdo con el género y muestra desigualdad económica entre hombres y mujeres. En el estudio El impacto de las políticas impositivas en el Ecuador: análisis desde la perspectiva de género, Campuzano y Palacios (2009) tomaron muestras de hogares con jefatura de ambos sexos para analizar parámetros de consumo, arrojando conclusiones como: en los hogares encabezados por mujeres se privilegia el gasto relacionado "en servicios del hogar", destinando mayor porcentaje de sus ingresos a los artículos de consumo diario para el bienestar y supervivencia del total de la familia. Los autores afirman que las mujeres privilegian 
los gastos relacionados con los medicamentos y el servicio doméstico y, por ende, sus ingresos se invierten en el gasto familiar y no individual, lo que se ve claramente con los datos obtenidos también en Colombia.

El análisis del consumo llevó el hilo conductor de esta investigación imperativamente a la canasta familiar. Teniendo presente que el valor de esta es un indicador a partir del cual se puede realizar un estudio que dé luces sobre la capacidad económica de las personas en Colombia, se hará una mirada sobre lo que se conoce como pobreza.

En Colombia, para determinar si se es pobre o no, se deben tener en cuenta dos métodos: el primero, que mide la pobreza monetaria, se determina al dividir el ingreso mensual por persona para saber si ese ingreso está por encima o por debajo de lo que se denomina Línea de Pobreza, lo cual se podría definir como el costo mínimo de una canasta básica de bienes, tanto alimentarios como no alimentarios. Para el año 2017, dicha línea se estableció en $\$ 250.620 /$ persona/mes. Así mismo, se obtiene el índice de pobreza extrema que solo tiene en cuenta el dinero necesario para adquirir alimentación sin tener en cuenta otros gastos no alimentarios, el cual, para el año 2017, era de $\$ 116.330$ por persona.

El segundo de los métodos incluye la medición de cinco dimensiones, a saber: condiciones educativas del hogar, condiciones de la niñez y la juventud, salud, trabajo, el acceso a los servicios públicos domiciliarios y las condiciones de la vivienda; estas dimensiones en conjunto arrojan los resultados de pobreza multidimensional.
En la Tabla 5 se puede notar que, en el año 2017 , el $29,7 \%$ de las personas que pertenecían a un hogar cuya jefatura era femenina, eran pobres; mientras que el $25,5 \%$ de las personas en hogares con jefatura masculina lo eran.

Tabla 5.

Tasa de incidencia en la pobreza según características del jefe de hogar - total nacional 2017

\begin{tabular}{|l|l|c|}
\hline \multicolumn{2}{|c|}{ Características del jefe de hogar } & $\begin{array}{c}\text { Total } \\
\text { Nacional }\end{array}$ \\
\hline \multirow{3}{*}{ Sexo } & Hombre & 25,5 \\
& Mujer & 29,7 \\
\hline \multirow{4}{*}{ Edad } & Hasta 25 años & 31,6 \\
& Entre 26 y 35 & 32,0 \\
& Entre 36 y 45 & 31,3 \\
& Entre 46 y 55 & 23,8 \\
& Entre 56 y 65 & 21,9 \\
Nivel & Mayor de 65 & 21,8 \\
\hline educativo & Ninguno o primaria & 36,9 \\
& Secundaria & 25,1 \\
& Técnica o Tecnológica & 10,9 \\
Situación & Universidad o Posgrado & 6,5 \\
\hline laboral & Desocupados & 47,8 \\
& & 25,6 \\
& Ocupados & 27,9 \\
\hline Posición & Inactivos & 14,2 \\
ocupacional & Asalariados & 34,8 \\
\hline \multirow{2}{*}{ Seguro social } & Patronos y cuenta propia & 36,8 \\
\hline \multirow{2}{*}{ Afiliado } & No Afiliado & \\
& &
\end{tabular}

Fuente: Elaboración propia a partir de Tasa de incidencia en la pobreza según características del jefe de hogar - total nacional (DANE, 2017, p. 17).

Las cosas no son diferentes con relación a la pobreza extrema. En el año 2017, a nivel nacional, el porcentaje de personas en condición de pobreza extrema fue del $8,7 \%$ cuando hacían parte de un hogar donde el jefe del hogar era mujer y de $6,7 \%$ cuando el jefe de hogar era hombre. 
Tabla 6.

Tasa de la pobreza extrema por características del jefe de hogar (porcentaje) - Total nacional Año 2017

\begin{tabular}{|l|l|c|}
\hline \multicolumn{2}{|c|}{ Características del jefe de hogar } & $\begin{array}{c}\text { Total } \\
\text { Nacional }\end{array}$ \\
\hline \multirow{5}{*}{ Sexo } & Hombre & 6,7 \\
& Mujer & 8,7 \\
\hline \multirow{4}{*}{ Edad } & Hasta 25 años & 10,6 \\
& Entre 26 y 35 & 9,0 \\
& Entre 36 y 45 & 8,8 \\
& Entre 46 y 55 & 5,6 \\
Nivel & Entre 56 y 65 & 6,1 \\
Educativo & Mayor de 65 & 5,9 \\
& Ninguno o primaria & 11,3 \\
& Secundaria & 5,7 \\
Situación & Técnica o Tecnológica & 2,4 \\
Laboral & Universidad o Posgrado & 1,7 \\
\hline Posición & Ocsocupados & 21,0 \\
Ocupacional & Inactivos & 6,3 \\
& Asalariados & 8,9 \\
\hline Seguro & Aatronos y cuenta propia & 1,4 \\
social & Afiliado & 0,3 \\
\hline & No Afiliado & 10,0 \\
\hline
\end{tabular}

Fuente: Tasa de la pobreza extrema por características del jefe de hogar (porcentaje) - Total nacional Año 2017 (2017) Boletín técnico Pobreza Monetaria y Multidimensional en Colombia Año 2017. Bogotá, Colombia. DANE (2017, p. 22).

En conclusión, son más pobres los hogares en los que la jefatura la ejerce una mujer. Aspecto que se encuentra condicionado al ingreso percibido por el o la aportantes económicos de ese hogar.

\section{ii. Otros aspectos relacionados con el consumo son:}

\section{Aspectos biológicos}

Lo apropiado cuando se distingue entre varón y hembra de la especie humana desde el punto de vista biológico es hablar de sexos, ya que este término se utiliza para describir características biológicas.
Muchos son los aspectos que diferencian anatómica y fisiológicamente a mujeres y hombres. Para efectos de este estudio, el centro de estas se dará como consecuencia de la diferenciación hormonal.

\section{Fecundidad}

De acuerdo con la OMS, las mujeres son fértiles aproximadamente 30 años de sus vidas (de los 12 años a los 48), lo que acarrea las siguientes consecuencias con repercusiones económicas:

- Genera la necesidad de utilizar productos de higiene femenina:

ONU Mujeres calcula que un $26 \%$ de la población mundial está en edad reproductiva. Es decir, son unos 1.800 millones de mujeres que cada mes menstrúan durante un periodo de entre dos y siete días. Si se establece una media de 4 días y se multiplica por 13 periodos al año se obtiene que durante 52 días al año las mujeres requieren de productos de higiene femenina. Dato que, si se quiere llevar a lo largo de la vida, arroja que durante 1.872 días las mujeres se ven obligadas a adquirir productos que inciden en su economía. De acuerdo con la publicación del periódico El Espectador (2017), la lucha contra el impuesto a toallas y tampones, para el año 2016 "el aporte de las mujeres en edad fértil al fisco era cercano a \$340.000 millones, por cuenta de los $\$ 160.000$ anuales destinados por cada una de ellas a la compra de productos higiénicos, aproximadamente una cuarta parte de un salario mínimo mensual de entonces". "Ese cálculo se hizo con base en las cerca de 25 toallas 
higiénicas - a \$500 cada una- que, durante cada uno de los 13 ciclos anuales, siguiendo las recomendaciones médicas, puede usar una mujer".

$\mathrm{Si}$ a esto se le suman otros productos de higiene de uso diario y el costo de los analgésicos que muchas mujeres ingieren para controlar el dolor producido, el cálculo del gasto mensual estaría por encima de la cifra arriba mencionada. Está claro que, como lo afirman Arias, Mansilla y Rincón (2017):

“... Los productos de protección femenina, como las toallas higiénicas, son bienes que sólo tienen un mercado objetivo, es decir, un único grupo al que se le pretende vender el bien, en este caso las mujeres...".

Y, por ende, la tasa del $5 \%$ que debe pagarse por concepto de IVA sobre el valor de esto afecta directamente a las mujeres.

Habría que preguntarse si un producto que es necesario para satisfacer necesidades elementales de la mayoría de la población colombiana, debería pertenecer a los productos de la canasta familiar y considerarse un producto esencial, bajo la óptica que su uso es además habitual y básico.

Los autores Arias, Mansilla y Rincón, ya mencionados, afirman que “... Un aumento en los precios de estos bienes afecta a un grupo en particular, a las mujeres de bajos recursos". Es aquí donde autores como Ochy Curiel (2011), culpan a el Estado heteronormativo patriarcal que, consciente o inconscientemente, emite leyes que oprimen a la población que no llena estas características...”.
La Corte Constitucional, en Sentencia C-117/2018 (noviembre 14). Expediente D- 12128. M.P. Gloria Stella Ortiz Salgado, declaró inexequible la partida 96.19 del artículo 185 de la Ley 1819 de 2016, que grava las toallas higiénicas y tampones con una tarifa de 5\% de IVA e incluyó estos productos en el listado de Bienes Excluidos del impuesto al valor agregado, contemplado en el artículo 175 de la Ley 1819 de 2016.

Con esta decisión, basada en los principios de equidad, igualdad y justicia tributaria, la Corte determinó que la inclusión del artículo 175 de la ya mencionada ley contenía aspectos discriminatorios a las mujeres y en especial a las mujeres más pobres, por cuanto la imposición del IVA se constituía como un impuesto creado por consumir "productos insustituibles" para ellas (toallas higiénicas y tampones), ya que no existen políticas públicas compensatorias que suplan la necesidad de estos bienes, para el caso de las mujeres con insuficiente capacidad económica.

Esta sentencia, aunque pueda llegar a ser inocua en cuanto al impacto económico en los productos, teniendo presente que si los mismos no se encuentran gravados, no pueden llevarse impuestos descontables, lo que en últimas termina afectando el precio al consumidor de los mismos; esta disposición jurisprudencial sí constituye un derrotero en análisis con enfoque de género dentro del sistema tributario y sin duda abre la puerta hacia otras consideraciones en ese aspecto.

Teniendo la sentencia ya analizada como punto de partida, se incluyó dentro del taxativo listado de productos excluidos a los tampones y toallas higiénicas, consagración legal que no fue modificada ni alterada por la Ley 1943 del 28 de diciembre de 2018. 
Adquisición de anticonceptivos

Aunque las resoluciones 769 de 2008 y 1973 de 2008 indican la obligatoriedad de los servicios de salud de informar, suministrar el método y brindar el seguimiento del uso de anticonceptivos en Colombia, no puede desconocerse que, debido a concepciones culturales, son las mujeres quienes en Colombia usan con mayor frecuencia métodos anticonceptivos.

Esto se evidenció en la Encuesta nacional de Demografía y salud (ENDS) en Colombia (2015), la cual arrojó los siguientes resultados:

\section{Tabla 7.}

Uso de métodos de planificación familiar por género en Colombia - 2015

\begin{tabular}{|l|c|c|}
\hline & $\begin{array}{c}\text { Usan } \\
\text { métodos de } \\
\text { planificación } \\
\text { familiar }\end{array}$ & $\begin{array}{c}\text { No usan } \\
\text { métodos de } \\
\text { planificación } \\
\text { familiar }\end{array}$ \\
\hline $\begin{array}{l}\text { Mujeres unidas } \\
\text { sexualmente activas }\end{array}$ & $80,9 \%$ & $19,1 \%$ \\
\hline Mujeres no unidas & $82,9 \%$ & $17,1 \%$ \\
\hline Promedio mujeres & $81,9 \%$ & $18,1 \%$ \\
\hline $\begin{array}{l}\text { Hombres unidos } \\
\text { sexualmente activos }\end{array}$ & $82,7 \%$ & $17,3 \%$ \\
\hline Hombres no unidos & $89,6 \%$ & $10,4 \%$ \\
\hline Promedio hombres & $86,15 \%$ & $13,85 \%$ \\
\hline
\end{tabular}

Fuente: Uso de métodos de planificación familiar por género en Colombia - (2015). Encuesta nacional de demografía y salud. ENDS Colombia, 2015. Bogotá, Colombia Minsalud.

La realidad reflejada en la tabla 7, a primera vista, indicaría que los hombres son quienes más usan y por ende adquieren los métodos de planificación familiar. Sin embargo, al adentrarse en los datos más específicos de la encuesta relacionados con la clase de método anticonceptivo usado, las cifras son las siguientes:
Tabla 8.

Métodos anticonceptivos usados por mujeres unidas.

\begin{tabular}{|l|c|}
\hline \multicolumn{1}{|c|}{ Anticoncepción } & $\begin{array}{c}\text { Porcentaje de muje- } \\
\text { res de 13 a 49 años } \\
\text { actualmente unidas }\end{array}$ \\
\hline Que está usando algún método & \\
anticonceptivo moderno & 75,9 \\
Que está usando algún método & \\
anticonceptivo & 80,9 \\
Esterilización femenina & 34,9 \\
Esterilización masculina & 3,6 \\
Píldora & 7,0 \\
DIU & 4,7 \\
Inyección mensual & 9,1 \\
Inyección trimestral & 5,1 \\
Implantes & 5,4 \\
Condón masculino & 5,8 \\
Ritmo & 2,0 \\
Retiro & 2,8 \\
\hline
\end{tabular}

Fuente: Profamilia (2016, p. 11).

Tabla 9.

Métodos anticonceptivos usados por hombres unidos

\begin{tabular}{|l|c|}
\hline Anticoncepción & $\begin{array}{c}\text { Porcentaje de hom- } \\
\text { bres de 13 a 49 años } \\
\text { actualmente unidas }\end{array}$ \\
\hline Que está usando algún método \\
anticonceptivo moderno \\
Que está usando algún método & 76,7 \\
anticonceptivo & 82,7 \\
Esterilización femenina & 30,4 \\
Esterilización masculina & 5,0 \\
Píldora & 7,3 \\
DIU & 4,1 \\
Inyección mensual & 10,0 \\
Inyección trimestral & 4,8 \\
Implantes & 6,2 \\
Condón masculino & 8,7 \\
Ritmo & 1,7 \\
Retiro & 4.1 \\
\hline
\end{tabular}

Fuente: Profamilia (2016,p. 12).

De lo anterior se puede concluir que la mayoría de los métodos usados por los hombres unidos y las mujeres unidas son femeninos, lo que permite presumir que son adquiridos por quienes los usan. 
$>$ Gastos relacionados con la menopausia

Aunque no existe tratamiento farmacológico necesario, ni cifras de cuantas mujeres acuden a suplementos hormonales, se sabe que por lo menos un $50 \%$ de las mujeres en las etapas previas y durante este cambio en la fisiología femenina, se ven obligadas por la presencia de molestias a usar terapia hormonal y a llevar una dieta diferente, lo que conlleva a ingerir suplementos nutricionales como, por ejemplo, de calcio.

Gastos durante el embarazo, parto y atención del bebe al nacer

Desde la prueba diagnóstica, las citas de control, las vitaminas prenatales, las ecografías, las vacunas son cuantiosos los gastos en que una pareja (en el mejor de los casos) debe incurrir para atender adecuadamente el embarazo. Para cuantificar ese valor no hay otra opción que recurrir a una publicación realizada por el periódico La opinión, de Cúcuta, en donde se realizó una cuantificación estratificada que arrojó siguientes resultados (véase tabla 10).

Según datos recopilados de la Encuesta longitudinal colombiana (Elca), de la Universidad de los Andes (2017), cerca de la mitad de las mujeres del país son madres solteras. Dato corroborado por el DANE (2017) cuando indica que el $56 \%$ de las mujeres colombianas son madres cabezas de familia y, de ellas, solo el 41,9\% tiene alguna ocupación laboral fuera del hogar.

Esto quiere decir que al $50 \%$ de las mujeres del país les corresponde incurrir en los gastos mencionados en la tabla 8 .

\section{iii. Mortalidad adulta}

Tradicionalmente se ha concebido que la esperanza de vida de hombres y mujeres es diferente. Para el año 2016, la esperanza de vida en Colombia subió hasta llegar a 74,38 años. Ese año la esperanza de vida de las mujeres fue de 78 años, mayor que la de los hombres que fue de 70,85 años. Según la ENDS - Colombia 2015, "En el total de los hogares encuestados se identificaron 165 defunciones que corresponden al 0,35 por ciento del total de la población, y en las mujeres de los hogares ocurrieron 91 defunciones, que corresponden al 0,17 por ciento del total de las mujeres, evidenciando que la razón de mortalidad hombre/mujer es igual a 1,7 hombres por cada mujer".

Igualmente, esta encuesta arrojó como resultado que el mayor índice de mortalidad masculina se daba en los grupos de 15 a 19 y de 25 a 29 años, con cifras de 4,19 y 4,62 , respectivamente, y a partir de los 30 años disminuye a medida que aumenta la edad. Ya que la principal causa de mortalidad masculina es por accidentes de tránsito y homicidios. "En las mujeres las causas car-

Tabla 10.

Costos de embarazo, parto y atención al bebe en Colombia por estratos

\begin{tabular}{|c|c|c|c|}
\hline Estrato socio-económico & Costo embarazo & Costo parto natural/cesárea & Gastos bebé \\
\hline 1 y 2 & 256.000 & $699.300 / 1.227 .300$ & 542.000 \\
\hline 3 y 4.428 .300 & $1.439 .300 / 2.539 .300$ & 2.181 .587 \\
\hline 5 y 6 & 10.409 .400 & $2.342 .000 / 4.342 .000$ & 5.808 .000 \\
\hline
\end{tabular}


diovasculares y las neoplasias están siendo las principales causas a partir de los 30 años (DANE, 2014)".

De lo anterior se puede concluir que las mujeres se ven obligadas a gastar en medicamentos y tratamientos médicos mayor cantidad de dinero y durante más tiempo que los hombres, ya que no solo alcanzan una edad más avanzada, sino que su autocuidado está disminuido dado que usualmente se ven afectadas por enfermedades crónicas que requieren un mayor gasto.

\section{Aspectos culturales}

- Impuesto rosa o Tasa Rosa

Hasta acá se ha demostrado estadísticamente que, por características biológicas o culturales, las mujeres hemos de consumir artículos de higiene y salud que no requieren los hombres. A esto se le suma que en Co- lombia también hay "Tasa Rosa" en varios productos de línea femenina, como desodorantes, vestuario y cuchillas de afeitar; concepto que es entendido como esa tasa invisible que incrementa el precio de los productos femeninos entre un 5\% a un 20\% en relación con el de los hombres o mixtos, afectando de nuevo la capacidad económica de las mujeres. Lo anterior, de acuerdo con el estudio política Fiscal y Género: que no se descargue la crisis sobre las mujeres, 2015 publicado en Red por la justicia Tributaria en Colombia y de autoría de Moreno Natalia y Plazas Clara.

Arias, Mansilla y Rincón (2017) plasmaron el siguiente relato que describe la aseveración anterior:

Laura, como todos los días, procede a bañarse y utiliza jabones corporales e íntimos, estos cuestan en promedio $\$ 15.000$. Debe utilizar una rasuradora rosada, "For Wo-

Tabla 11.

Factores asociados a la mortalidad por enfermedades no transmisibles según sexo. Colombia 2008 - 2012

\begin{tabular}{|l|c|c|c|c|c|c|}
\hline & \multicolumn{3}{|c|}{ Sexo } & \multicolumn{2}{c|}{ X2 } & P \\
\hline & \multicolumn{2}{|c|}{ Hombre } & \multicolumn{2}{|c|}{ Mujer } & & \\
\hline & Frecuencia & $\mathbf{\%}$ & Frecuencia & \% & & \\
\hline Enfermedades no transmisibles & & & & & & \\
\hline Causa externa & 66.810 & 26,33 & 11.384 & 5,67 & & \\
\hline Diabetes mellitus & 9.740 & 3,84 & 12.788 & 6,37 & & \\
\hline $\begin{array}{l}\text { Enfermedades de las vías respiratorias } \\
\text { inferiores }\end{array}$ & 18.811 & 7,41 & 16.972 & 8,46 & $34.247(4)$ & $<0,001$ \\
\hline Enfermedades del sistema circulatorio & 96.466 & 38,01 & 93.442 & 46,56 & & \\
\hline Neoplasias (tumores) & & & & & & \\
\hline Total general & 61.934 & 24,41 & 66.105 & 32,94 & & \\
\hline
\end{tabular}


man”, por la cual paga $\$ 11.050$ pesos, $\$ 700$ pesos más que la equivalente en azul oscuro. ¿La razón de la diferencia en precios? Su color, quizá. ¿Su alternativa? Usar una crema depilatoria que se vende en promedio a \$15.000. ¿Permanecer con pelos en las piernas, axilas, cara y casi cualquier otra parte del cuerpo que no sea su cabeza (en donde debe invertir otra suma de dinero)?

Inimaginable, sería una humillación para ella. Aunque estos productos son de uso diario para mujeres como Laura, en Colombia aún son denominados como "artículos de lujo" y, por esto, en la actualidad tienen un IVA del 19\%. El IVA y la variación de los precios en artículos, como la rasuradora etiquetada "For Woman", hace que las mujeres paguen más por su cuidado personal que los hombres.

Según los estudiosos del tema, la diferencia de precios entre los productos "azules" y "rosas" o para hombres y para mujeres, puede ser mínima. Podrían ser unos pocos pesos los que se paguen de más. El problema es que se da en la mayoría de productos diferenciados por género, también se da frecuentemente en peluquerías donde los precios para mujeres son mucho más elevados que para los hombres.

Hay empresarios que afirman que el movimiento del mercado -la demanda en específico para este caso- es lo que regula el precio y que las mujeres consumen más de estos productos y, por ende, generan ellas el alza de los precios. Lo cierto es que se paga un precio más elevado y esto afecta la economía de ellas. Así mismo, esa diferenciación en precio la realizan las empresas sin advertir al consumidor de tal realidad.
Arias, Mansilla y Rincón (2017), ante la falta de estudios de esta clase en Colombia, acuden a investigaciones de Estados Unidos para determinar que también existe impuesto rosa en las prendas de vestir; así lo expresan los autores:

Una investigación, realizada por el New York City Department of Consumer Affairs, confirmó que las mujeres pagan en promedio $8 \%$ más por prendas de las mismas marcas en comparación con su contraparte masculina. Aun peor, estas prendas "feminizadas" contienen menos producto en sí, ya que usualmente las vestimentas son recortadas y estilizadas. Ocurrió que este fenómeno se tornó tan común que ya existe una expresión en inglés para esto: "Shrink it and pink it" que traduce Encógelo y vuélvelo femenino" (Taylor, 2016). Esta misma institución neoyorquina comparó más precios para distintos productos y descubrió que esta diferencia ficticia surgía desde la infancia. Las niñas deben pagar, según este reportaje, $4 \%$ más que los niños para la ropa y $7 \%$ más en juguetes diseñados especialmente para las "mamás" del futuro. Esta tendencia de precios altos en los productos "rosas" no solo ocurre en Nueva York.

Negar que existe esta tasa sería un absurdo cuando para el mundo entero es una realidad y, además, una situación absolutamente injusta que debe erradicarse cuanto antes. En España, en julio de este año, la ministra de Hacienda María Jesús Montero, afirmó ante el congreso español que, dentro de los objetivos y planes en materia fiscal del Gobierno de Pedro Sánchez, está como prioridad eliminar la denominada tasa rosa sobre productos de higiene femenina y otros productos que consumen directamente las mujeres. En 
Francia, los consumidores que han palpado la realidad del impuesto rosa, han creado movimientos y colectivos para que el ciudadano en general conozca que el problema existe y se acabe con la práctica. Como parte de las estrategias, la organización Georgette Sand tiene una cuenta en Tumblr a través de la cual invita a los consumidores a subir fotos de los productos que encuentren en el mercado y que posean la tasa. A través de las denuncias y la recolección de firmas, piden al gobierno que se tomen las medidas para eliminar ese valor agregado que han denominado sexista.

\section{B. Consideraciones finales}

Hasta acá se analizaron tres elementos con los cuales se podría concluir que la capacidad económica entre hombres y mujeres es desigual, ya que los hombres poseen más patrimonio declarado, más ingresos y sus tendencias de consumo (compras) con destinación a la familia son inferiores a la de sus congéneres del género femenino. Igualmente, se demostró que existen otros factores de incidencia como los impuestos directos que afectan de forma diferente a hombres y a mujeres. Lo que de acuerdo con lo planteado en el primer párrafo de este trabajo al citar el trabajo de Ávila y Cruz (2006) afecta la progresividad.

Si se aplicara un método lógico-deductivo a lo desarrollado por este trabajo, podría llegarse a plantear lo siguiente: si la capacidad económica es la base para la configuración de sistemas tributarios progresivos y la capacidad económica entre hombres y mujeres no es similar, no es progresivo tratar (tributariamente hablando) a hombres y a mujeres en igualdad. Debe, entonces, reco- nocerse que la afirmación de Moreno y Plazas (2015) "equidad no es igualdad", inserta en la página 8 de su trabajo Política fiscal y género, es real. Un tratamiento igualitario u homogéneo, en cuanto al impuesto de renta de personas naturales entre hombres y mujeres, no es equitativo porque desconoce las diferencias que existen entre los sujetos; es decir, la generalidad desconoce la equidad vertical.

Así mismo, Pazos y Rodríguez (2010) desarrollan una idea similar al expresar que las políticas fiscales y específicamente los sistemas tributarios, son útiles herramientas para la equidad de género. Esto, si logran atender las necesidades de la ciudadanía según sus prioridades y proporcionar incentivos económicos para condicionar el comportamiento de las personas. Comportamiento que culturalmente debe cambiar a familias con personas sustentadoras/cuidadoras en igualdad.

No pueden entonces el Derecho fiscal, las políticas fiscales y tampoco los sistemas tributarios, específicamente los impuestos, desconocer que están llamados a tener enfoque de género.

En Colombia, el desarrollo del pensamiento de impuestos relacionados con equidad de género se suscitó desde la expedición de la Constitución Política de 1991, que contempló en el artículo 43 la igualdad de derechos entre hombres y mujeres. Iniciando, así, la inquietud intelectual relacionada con temas de género en campos diversos a la familia o al campo laboral. Tan novedoso es el análisis en el tema tributario que, apenas a propósito de la expedición de la Ley 1819 de 2016, se suscitó la controversia relacionada con el IVA aplicado sobre los artículos de higiene feme- 
nina, controversia que aún no cesa, pero que muchos consideran descabellada.

Mientras que, en otros países, como Estados Unidos, España, Argentina o Chile, se ha trabajado la tributación y en específico el sistema tributario desde la óptica de género, pensando siempre en "establecer políticas tributarias y presupuestales con enfoque de género, que sean eficientes, dinámicas y generales, lo cual implica la no neutralidad de la política fiscal, para poder reconocer los efectos diferenciados entre hombres y mujeres" (Moreno y Plazas, 2015, p. 6).

Conocemos actualmente las constantes actuaciones emprendidas por organizaciones como la ONU que, a partir de la Cuarta conferencia de la Mujer en 1995, asumió que el empoderamiento de la mujer y la promoción de la equidad de género son herramientas para erradicar la pobreza y mejorar las condiciones sociales y políticas de la sociedad en su conjunto. Medida que fue ratificada en el 2015 en la Cumbre para el desarrollo sostenible. Actuaciones de la CEPAL, que trasladó a América Latina y el Caribe mediante las conferencias que realiza cada dos años las inquietudes relacionadas con la integración de la mujer al desarrollo económico y social (1977) y la prevención y corrección de desigualdades que discriminan a las mujeres (2012). Y, finalmente, tareas adelantadas por la OCDE, que ha convocado a sus países miembros a diseñar medidas que consulten el enfoque de género tanto en sus ingresos como en sus gastos. Todo esto demuestra que sugerencias, estadísticas que respaldan la necesidad de la toma de medidas eficientes y análisis de la incidencia en la sociedad de medidas que consulten la equidad de género en campos económicos y fiscales ha habido muchos, conclusiones varias y de suma importancia, pero, para el caso de Colombia, realidades concretas muy pocas, ya que para este caso equidad fiscal no es igualdad.

Entonces, la realidad desigual plasmada no es un descubrimiento de este trabajo, es la constatación del llamado que durante décadas han efectuado diferentes organismos internacionales, como los ya mencionados. En vía de ejemplo se cita lo que en la CEDAW (siglas en inglés de la Convención sobre la Eliminación de Todas las Formas de Discriminación contra la Mujer o CETFDCM) se instó a los estados miembros de la ONU a través de este importante tratado internacional:

La revisión del sistema tributario desde la perspectiva de la CEDAW implica evaluar no solo que el total recaudado sea suficiente para asegurar el ejercicio de los derechos civiles, políticos, económicos, sociales y culturales para varones y mujeres en condiciones de igualdad, sino también que estos recursos sean recaudados de una manera consistente con el objetivo de alcanzar la igualdad sustantiva" (Gherardi y Rodríguez, 2008, p. 2).

En el trabajo precitado, se concluye que esa "equidad sustancial" debe ir más allá de la equidad horizontal y hacia una equidad vertical. Empleando diferentes tratamientos tributarios a diferentes grupos, transformando los impuestos en una verdadera herramienta distributiva de riqueza, protegiendo a la población más vulnerable y "transformando las inequitativas relaciones de género existentes" (Gherardi y Rodríguez, 2008, p. 4). 
Estos aspectos llevan a pensar en la disparidad en cuanto a las capacidades económicas y a plantear la idea de que no pueden catalogarse como iguales (desde el punto de vista legal y fiscal) a quienes no lo son. Las políticas fiscales deben ser sensibles al género, ya que actualmente no cumplen con el objetivo de redistribuir el ingreso y su estructura es inequitativa. Además, se encuentra principalmente fundado en la eficiencia del recaudo y no en la relación real entre la capacidad económica y de tributación. Hipótesis que debe ser confrontada desde la academia y analizada a la luz del Derecho fiscal para ser confirmada, replanteada o rechazada.

\section{Los principios de universalidad y equidad vertical dentro del análisis de género del impuesto de renta en personas naturales}

El sistema tributario, entendido como la organización legal (y por ende normativa), administrativa y económica creada para ejercer la potestad tributaria en forma objetiva y eficiente, tiene, como lo señala Alexander Medina Rincón en su obra La ponderación y el análisis económico del Derecho (2013), citando a Dworking y Alexy, "razones de decisión" que actúan como "estándares" o "mandatos de optimización" de aplicación directa que, además de fundamentar la decisión, se encuentran claramente contenidos de "valores" que deben ser perseguidos por el Estado de acuerdo a la concepción dogmática del mismo.

Para el caso del Estado colombiano, la jurisprudencia constitucional ha manifestado que el sistema tributario se encuentra fundamentado en lo consagrado por la Cons- titución de 1991, carta política por la que Colombia se erige como Estado Social de Derecho, y en el desarrollo de la misma. Así lo expresó en la Sentencia C 495 de 1995:

Estado Social de Derecho. Principios tributarios. La función de las autoridades es no sólo proclamar los derechos fundamentales sino, y tal vez, sobre todo, hacer efectivos esos derechos en la vida cotidiana de las personas. Sólo de esa manera se puede lograr que la igualdad entre las personas sea real y efectiva. Ahora bien, para poder desarrollar sus actividades, cumplir sus fines y realizar los valores que encarna el ordenamiento constitucional, las autoridades públicas requieren permanentemente de recursos, puesto que no sólo ciertas necesidades sólo pueden ser satisfechas mediante prestaciones públicas sino que, además, muchos de los derechos fundamentales que en apariencia implican un deber estatal de simple abstención -los llamados derechos humanos de primera generación o derechos civiles y políticos- en la práctica requieren también intervenciones constantes del Estado. En efecto, el goce de estos derechos por las personas requiere, por ejemplo, una eficaz administración de justicia y una diligente labor de la Fuerza Pública, a fin de que se garantice una convivencia pacífica entre los colombianos" (Corte Constitucional de Colombia, sentencia 445 de 1995).

Siendo entonces la parte dogmática de nuestra Constitución el marco inspirador y regulador del sistema tributario, cabe la pregunta ¿Cuáles son los principios del Derecho tributario en Colombia? Y ha sido el mismo órgano constitucional el que los ha determinado y reafirmando en variada jurispruden- 
cia. Es así como en la sentencia C 913/11 la

Corte constitucional manifestó:

De acuerdo con el artículo 363 de la Constitución, el sistema tributario se funda en los principios de equidad, eficiencia y progresividad, los cuales constituyen el marco general que guía la imposición de las cargas fiscales a través de las cuales el Estado obtiene los recursos necesarios para su consecución y funcionamiento. Es importante tener en consideración que los principios de equidad, eficiencia y progresividad son predicables del sistema tributario en su conjunto y no de un impuesto en particular. En estos términos, para la Corte tales principios "constituyen los parámetros para determinar la legitimidad del sistema tributario y, como ha tenido oportunidad de precisarlo esta Corporación, se predican del sistema en su conjunto y no de un impuesto en particular.

El principio de equidad tributaria ha sido definido por la Corte como una manifestación específica del principio general de igualdad y comporta la proscripción de formulaciones legales que establezcan tratamientos tributarios diferenciados injustificados, ya sea porque se desconozca el mandato de igual regulación legal cuando no existan razones para un tratamiento desigual, o porque se desconozca el mandato de regulación diferenciada cuando no existan razones para un tratamiento igual. El principio de progresividad tributaria dispone que los tributos han de gravar de igual manera a quienes tienen la misma capacidad de pago (equidad horizontal) y han de gravar en mayor proporción a quienes disponen de una mayor capacidad contributiva (equidad vertical). En cuanto al principio de eficiencia, también ha considerado la Corte, que "resulta ser un recurso técnico del sistema tributario dirigido a lograr el mayor recaudo de tributos con un menor costo de operación; pero de otro lado, se valora como principio tributario que guía al legislador para conseguir que la imposición acarree el menor costo social para el contribuyente en el cumplimiento de su deber fiscal (gastos para llevar a cabo el pago del tributo).

Esta transcripción jurisprudencial es útil para determinar cómo el máximo órgano constitucional ha identificado en general los principios que rigen el sistema tributario. De ellos se podría afirmar que tocan directamente el tema de este trabajo dos grupos de principios: se tomara entonces, por un lado, los principios de igualdad y generalidad y, por el otro, el principio de progresividad desde el punto de vista de la equidad vertical

\section{A. Igualdad-generalidad}

El artículo 95 de la Constitución Política establece dentro de los deberes de los ciudadanos colombianos el "contribuir" para el financiamiento de los gastos del estado de la siguiente forma:

Art. 95. - La calidad de colombiano enaltece a todos los miembros de la comunidad nacional. Todos están en el deber de engrandecerla y dignificarla. El ejercicio de los derechos y libertades reconocidos en esta Constitución implica responsabilidades. Toda persona está obligada a cumplir la Constitución y las leyes. Son deberes de la persona y el ciudadano:

(...). 9. Contribuir al financiamiento de los gastos e inversiones del Estado dentro de conceptos de justicia y equidad" 
Con base en esa obligación, dentro del presupuesto general de la nación se ha establecido una categoría o cuenta de ingresos denominada por la ley orgánica de presupuesto como ingresos corrientes y que se encuentra constituida por los ingresos tributarios que se obtienen al recaudar los impuestos de la nación y por los ingresos no tributarios que corresponden fundamentalmente a las tasas y las multas impuestas por la nación.

Si vamos a la realidad, el tratadista Sarmiento L., en marzo de 2018 escribió un artículo llamado Colombia. Presupuesto General de la nación, en el cual menciona la siguiente información:

El PGN 2018 se financia principalmente con dos fuentes: los tributos que paga la clase trabajadora a través de los impuestos indirectos (IVA, impuestos al consumo y la gasolina, gravámenes a los movimientos financieros), que suman el 55,5\% de los ingresos corrientes de la Nación; la otra fuente significativa es el crédito, interno y externo, que adquiere el Estado; para 2018 el endeudamiento nuevo ( $\$ 68,3$ billones; $30,8 \%$ del total del PGN)...

Los ingresos corrientes de la Nación se dividen en tributarios (directos e indirectos) y no tributarios (tasas, multas y contribuciones). Los tributarios son los más importantes, aportan el 99,5\% (\$139,3 billones).

Los ingresos tributarios integran los impuestos directos (renta y complementarios), con una contribución del 44,2\% (\$61,6 billones), y los impuestos indirectos, con un aporte del 55,8\% (\$77,7 billones). Las cuentas que más aportan a los tributos indirectos son el impuesto al valor agregado, IVA, con el $77,8 \%$ ( $\$ 60,4$ billones) y el gravamen a los movimientos financieros, GMF, que de acuerdo con la Ley 1819 de 2016 mantiene su tarifa en 4 por mil de manera indefinida, cuyo recaudo representa el 10,3\% para 2018 (\$8 billones). Las demás cuentas de los impuestos indirectos (al consumo, a la gasolina y al Acpm, sobre aduanas, al carbón y otros) contribuyen con el 11,9\% (\$9,3 billones) remanente.

Entonces, si se concreta en el contexto económico nacional el deber de contribuir -generalidad (igualdad formal)-, ya que somos los ciudadanos colombianos por vía impuestos tasas y contribuciones quienes aportamos 59,4\% (porcentaje de ingresos corrientes dentro del presupuesto nacional 2018) de la financiación de nuestro Estado.

Podría decirse, tal como se han planteado las cosas, que como lo expresa la Corte Constitucional en la C-209 de 2016: "uno de los deberes más importantes de los ciudadanos es el de "contribuir al financiamiento de los gastos e inversiones del Estado dentro de los conceptos de justicia y equidad".

Siendo ese deber la base de la potestad de establecer tributos en sus modalidades de impuestos, tasas y contribuciones que la constitución otorga al Congreso de la República.

Es a través de los tributos como el Estado puede "garantizar un orden político, económico y social justo, cumplir los deberes sociales y los fines esenciales como la efectividad de los principios, derechos y deberes constitucionales".

Entonces, si una determinada persona (sujeto pasivo) se encuentra inmersa en una 
situación que lo obliga a contribuir (hecho generador), debe hacerlo sin importar distinción alguna, ya que la admisión de exenciones y beneficios fiscales aminoran el principio de generalidad, teniendo presente que la igualdad exige equidad en la imposición y también tiene relación con la eficiencia en la fiscalización y en el recaudo de los tributos, ya que es menos costoso para el Estado que todos contribuyan y se tengan patrones generales con los cuales medir a todos los ciudadanos, en lugar de realizar distinciones a determinados grupos que dificultan la labor administrativa.

\section{B.Progresividad - equidad vertical}

Este principio, que encuentra su fundamento constitucional (expreso) en el artículo 363 de la Constitución Política, guarda estrecha relación con la capacidad contributiva, ya que implica que, a medida que aumente la riqueza del sujeto pasivo, mayor debe ser la proporción de financiación del gasto público que se le exija. Teniendo que si bien los impuestos son el medio para la obtención de recursos por parte del Estado, también deben ser un instrumento para la realización de la redistribución de la riqueza.

Cabe recordar que la progresividad no puede exigirse de cada impuesto, sino que debe predicarse del sistema en general.

Romero Molina, Grass Suárez y García Caicedo (2013) así lo argumentan:

Con respecto al principio de progresividad, la Corte, en Sentencia C-173 del 2010 ha manifestado que: [...] hace referencia al reparto de la carga tributaria entre los diferentes obligados a su pago, según la capacidad contributiva de la que disponen, es decir, es un criterio de análisis de la proporción del aporte total de cada contribuyente en relación con su capacidad contributiva. En este orden de ideas, es neutro el sistema que conserva las diferencias relativas entre los aportantes de mayor y de menor capacidad contributiva; es progresivo el que las reduce; y es regresivo el que las aumenta.

El principio de progresividad proviene del principio de equidad vertical, dado que reconoce el justo reparto de la carga tributaria entre los diferentes obligados, aporte que debe encontrarse ajustado y limitado por la capacidad contributiva de ellos. Es así como, por ejemplo, se exige que la tributación no vaya a afectar el mínimo vital (como límite mínimo), así las cosas, se ha entendido que el principio de progresividad y el de equidad vertical concurren en la medida en que ambos se imponen una distribución de las cargas y obligaciones que impone el sistema tributario, así como de los beneficios que este genera (Sentencia C-776 de 2003, M.P. Manuel José Cepeda Espinosa).

La misma sentencia inmediatamente antes mencionada define el principio de equidad como "un criterio más amplio e indeterminado de ponderación, relativo a la forma como una disposición tributaria afecta a los diferentes obligados o beneficiarios a la luz de ciertos valores constitucionales".

Esto de frente a la equidad horizontal, que consiste en que personas con capacidad económica o presupuesto fáctico similar deben contribuir de igual manera al financiamiento de los gastos e inversiones del Estado (CP art. 95-9). Para concretarse la equidad horizontal debe darse trato igualitario a personas 
en situaciones idénticas. Trato igual para los iguales.

La equidad vertical demanda en cambio que las personas con más capacidad económica contribuyan en mayor proporción, para que el sacrificio fiscal sea similar incluso entre sujetos con capacidades de pago desiguales. Por lo mismo, la Corte ha señalado que la Constitución exige gravar "en mayor proporción a quienes tienen mayor capacidad contributiva -equidad vertical-, a fin de que, a la postre, todos acaben haciendo un igual sacrificio de cara a sus capacidades" (C-100 de 2014). Este principio implica brindarle trato diferenciado a quienes se encuentran en situaciones no idénticas. Es decir, trato diferente a los diferentes.

En el aparte anterior se demostró que, con base en los factores analizados, la capacidad económica (vista desde los aspectos de análisis, como fueron: patrimonio, ingresos y consumo) entre hombres y mujeres no es similar. Por ende, no es posible aplicarse el principio de equidad horizontal y mucho menos el principio de igualdad, generalidad del Derecho tributario que es el que actualmente opera. (Así quedó demostrado en el capítulo I, al concluir que no existe, ni han existido tratamientos diferenciales en el impuesto de renta personas naturales entre hombres y mujeres a lo largo de la historia legislativa de este país).

Entonces cabría el siguiente cuestionamiento, la generalidad en la tributación que trata a todos los ciudadanos colombianos como iguales y no diferencia entre hombres y mujeres, facilitando procesos administrativos y mejorando el recaudo del impuesto de renta, volviendo realidad la idea de obli- gación general para el sostenimiento de los fines del Estado colombiano, debe ser "sacrificada" por un reconocimiento no uniforme al entrar a considerar que la capacidad económica de hombres y mujeres no es igual y que por ende, debe darse un tratamiento diferenciado?

\section{Ejercicio de ponderación}

Siguiendo la metodología planteada por la Corte Constitucional y con base en lo desarrollado en sentencias como C-445 de 1995 , C-183 de 1998 y la C-748 de 2009, en donde se admite posibilidad de tratos desiguales del orden general en materia tributaria y también implementando el AED (análisis económico del Derecho) que Medellín A. plantea en su obra “ponderación y Análisis Económico del Derecho" (2013), se realizará el ejercicio de ponderación de los principios en conflicto, estos son: la Universalidad y El principio de equidad vertical.

Teniendo en cuenta que Medellín (2013) define la ponderación como “... un mecanismo con el que es posible determinar, ante la colisión de dos principios en conflicto, cuál de ellos tiene un peso superior...", se procederá a establecer cada uno de los pasos del mecanismo (siguiendo el proceso planteado con las sentencias analizadas en el capítulo 3 de la obra):

1. Determinar si hay dos principios en conflicto:

No es posible dar aplicabilidad simultánea a los dos principios, ya que el reconocimiento de la equidad vertical implicaría necesariamente la aplicación de tratos diferenciados que con- 
secuencial y evidentemente irían en contra de la Universalidad del Derecho tributario.

Esta aseveración podría dibujarse así:

Reconocimiento Equidad Vertical $\Rightarrow$ tratos tributarios Diferenciados

Tratos diferenciados $\notin$ Principio de universalidad del Derecho tributario.

Por tanto, existe conflicto entre dos principios al no poder darse su aplicación simultánea, estos son:

$>$ Principio de universalidad de la obligación de contribuir para el financiamiento de los fines del estado (Art. 95 -9 C.P.), que para efectos del ejercicio se denominará $\mathrm{P} 1$

$>$ Principio de equidad vertical (Art.363 C.P.) que se denominará $\mathrm{P}_{2}$

2. Aplicación de la fórmula del peso de los principios:

“... Mediante tres variables se busca determinar el grado de precedencia de un principio con respecto a otro..." (Medellín, 2013, ob. cit.) permite analizar dos principios para conocer el grado de sacrificio de un principio con relación al otro, la importancia de protección de cada uno y por último si la restricción de un principio se justifica dada la importancia del otro.

\section{a. Grado de afectación (A)}

Indica qué tanto se afecta un principio con respecto del otro.
La afectación de $\mathrm{P} 1$ es grave al reconocerse el $\mathrm{P}_{2}$, ya que implica dificultades para la auditoría y fiscalización del impuesto y, lo que es peor, implicaría probablemente una mayor posibilidad de evasión. Estos dos aspectos necesariamente conllevan menor recaudo y aumentar el déficit fiscal de nuestro Estado, entones se representaría según la escala tríadica como $2^{1}$.

Ahora, en el análisis inverso, la afectación del $\mathrm{P}_{2}$ al continuarse bajo el $\mathrm{P}_{1}$ es moderada, ya que las personas naturales poseen algunos beneficios como las deducciones por dependientes o por el pago de empleados a cargo, por ejemplo, las personas contratadas para el desarrollo de la economía de cuidado que podrían hacer valer que si bien no subsanan las diferencias en cuanto a la capacidad económica, sí podrían en algo equiparar económicamente los gastos sufragados con lo dejado (en virtud de la deducción) de tributar. Representada con $2^{1}$

En consecuencia, la primera variable de ponderación se debe expresar así:

$$
\begin{aligned}
& \mathrm{A}_{(\mathrm{p} 1, \mathrm{p} 2)}=2^{2} / 2^{1}=4 / 2=2 \\
& \mathrm{~A}_{(\mathrm{p} 2, \mathrm{p} 1)}=2^{1 /} / 2^{2}=2 / 4=0.5
\end{aligned}
$$

b. Peso abstracto (W)

Partiendo de la jerarquía de cada principio dentro del ordenamiento jurídico, se busca establecer el grado de importancia de estos, en relación con los valores del conglomerado social. 
La universalidad del tributo $\left(\mathrm{P}_{1}\right)$ tiene un peso leve en cuanto a su importancia debido a que hace regresivo el impuesto de renta. Mientras que la equidad vertical $\left(\mathrm{P}_{2}\right)$ tiene una importancia más intensa o superior al contribuir a la progresividad del impuesto, haciendo que lo que se encuentra en juego sea la menor o mayor finalidad de redistribución del ingreso que debe primar en el sistema tributario y que mejoraría las condiciones económicas de la sociedad y el acceso a bienes y servicios.

Entones para $\mathrm{P}_{1}$ el peso abstracto leve implica un $2^{0}$; mientras que para $\mathrm{P}_{2}$, el peso abstracto superior o intenso se representaría con $2^{2}$.

Así las cosas, la segunda variable de ponderación se expresa así:

$$
\begin{aligned}
& \mathrm{W}_{(\mathrm{p} 1, \mathrm{p} 2)}=2^{0} / 2^{2}=1 / 4=0.25 \\
& \mathrm{~W}_{(\mathrm{p} 2, \mathrm{p} 1)}=2^{2} / 2^{0}=4 / 1=4
\end{aligned}
$$

c. Seguridad de las premisas fácticas (S)

La fórmula pretende expresar el grado de certeza que genera el que con el favorecimiento de un principio se afecta el otro.

Hay mayor seguridad que restringiendo la universalidad tributaria al reconocer la preponderancia del principio de seguridad vertical y permitiendo tratos diferenciales entre hombres y mujeres en relación con el impuesto de renta, protegiéndose derechos como la progresividad, la equidad, la propie- dad privada. A la vez, hay que ver que existen, como ya se había mencionado, otros mecanismos tributarios para que determinados aspectos de la vida económica de las personas naturales sean llevados al ámbito tributario y que la vulneración al principio de la universalidad afecta la eficiencia, la simplicidad y la igualdad o generalidad del sistema. Podría afirmarse entonces que tanto $\mathrm{P}_{1}$ como $\mathrm{P}_{2}$ se verían afectados. Viéndose gráficamente así:

$$
\mathrm{S}_{(\mathrm{p} 1, \mathrm{p} 2)}=2^{0} / 2^{0}=1 / 1=1
$$

$\mathrm{S}_{(\mathrm{p} 2, \mathrm{p} 1)}=2^{0} / 2^{0}=1 / 1=1$

La fórmula del peso con sus tres variables para el principio de universalidad $\mathrm{P}_{1}$ quedaría así:

$$
\mathrm{P}_{(\mathrm{p} 1, \mathrm{p} 2)}=4 / 2 * 1 / 4 * 1 / 1=4 / 8=0.5
$$

Ahora bien, la fórmula del peso como expresión numérica para el principio de equidad vertical sería:

$\mathrm{P}_{(\mathrm{p} 2, \mathrm{p} 1)}=2 / 4 * 4 / 1 * 1 / 1=8 / 4=2$

Producto de estos resultados, se puede concluir que el peso del principio de universalidad es de 0,5 , mientras que el peso del principio de equidad vertical es de 2. Existe mayor peso en el segundo principio que en el primero, pero la diferencia es mínima, por lo que debe darse la protección al principio de equidad vertical, restringiendo levemente el otro para mantener de cierta forma el equilibrio, ya que su peso es más o menos similar. 
En este caso, tratando de otorgar mayores argumentos y otorgándole mayor objetividad al ejercicio de ponderación, tal como lo plantea Medellín (2013) en su obra ya tantas veces citada, se continuará con el desarrollo de las dos variables incluibles dentro del ejercicio para determinar los costos económicos de la prevalencia de un principio sobre el otro.

d. Costos de protección de un principio sobre el otro (C)

Se relaciona esta variable con los costos en los que se vería obligado el Estado a incurrir para la protección de cada derecho, permitiendo medir el comportamiento económico de la asignación de cada derecho.

La asignación del principio de universalidad no tendría costos, ya que es el principio imperante en la actualidad, mientras que la equidad vertical ampliaría estudios algo complejos al interior del gobierno, discusiones en el legislativo, capacitaciones para los administradores tributarios y el conglomerado social en general, implementación de tecnología y personal para su fiscalización y recaudo; es decir, costos elevados.

La representación gráfica sería:

$\mathrm{C}_{(\mathrm{p} 1, \mathrm{p} 2)}=2^{-1 / 2^{2}}=0.5 / 4=0.125$

$\mathrm{C}_{(\mathrm{p} 2, \mathrm{p} 1)}=2^{2} / 2^{-1}=4 / 0.5=8$

e. Efectos Económicos en el largo plazo, con respecto al precedente $(\mathrm{EE})$
Este análisis lleva a establecer una valoración sobre las consecuencias de la decisión, robusteciendo la objetividad de la argumentación, teniendo en cuenta los efectos a futuro que tendría el sacrificio de un principio frente al otro.

Al continuar bajo la prevalencia del $\mathrm{P}_{1}$ seguirían viéndose vulnerados $\mathrm{y}$ desconocidos los derechos de las personas naturales (hombres y mujeres), al ser regresivos y no consultar las reales implicaciones de la relación entre capacidad económica e impuesto de renta. Creando un incentivo negativo en relación con las óptimas relaciones sociales y económicas entre hombres y mujeres, ya que los hombres se ven premiados económicamente y esto podría estimular las relaciones inequitativas que han venido existiendo en las familias y en la sociedad en el largo plazo, generando costos sociales muy altos que traerían consecuencias económicas para el estado $\left(2^{2}\right)$.

Tomar las medidas para hacer realidad el principio de equidad vertical $\mathrm{P}_{2}$ tendría a largo plazo un efecto positivo sobre la economía, ya que, como se mencionó, mejora la redistribución del ingreso, permitiendo que las mujeres y los hombres en iguales (no uniformes) condiciones aporten al mantenimiento del Estado. Mejorando las estructuras sociales desde las relaciones familiares y disminuyendo el deber asistencial del estado, lo que redundaría en un mejoramiento del ciclo económico $\left(2^{0}\right)$.

$\mathrm{EE}_{(\mathrm{p} 1, \mathrm{p} 2)}=2^{2} / 2^{0}=4 / 1=4$ 
$\mathrm{EE}_{(\mathrm{p} 2, \mathrm{p} 1)}=2^{0} / 2^{2}=1 / 4=0.25$

Solo resta unir las fórmulas del peso con los elementos del AED para obtener una visión total de la valoración de los principios en conflicto.

La fórmula del peso + AUE para el principio de universalidad $\mathrm{P}_{1}$ quedaría así:

$\mathrm{P}_{(\mathrm{p} 1, \mathrm{p} 2)}=4 / 2 * 1 / 4 * 1 / 1 * 0.5 / 4 * 4 / 1=$ $8 / 32=0.25$

Ahora bien, la fórmula del peso como expresión numérica para el principio de equidad vertical sería:

$\mathrm{P}_{(\mathrm{p} 2, \mathrm{p} 1)}=2 / 4 * 4 / 1 * 1 / 1 * 4 / 0.5 * 1 / 4=$ $32 / 8=4$

La incorporación de las dos variables aumentó la distancia del peso del principio de equidad vertical en relación con el principio de universalidad del tributo, lo que podría en dado caso aumentar las posibilidades de protección del primero mencionado sobre el segundo, ya que es a largo plazo cuando se verán los resultados sociales y económicos de esa prevalencia. A corto plazo podría verse afectado el recaudo y disminuidos los recursos, pero a largo plazo mejoraría la calidad de vida, la equidad de las relaciones y también el ciclo económico.

\section{Conclusiones}

La capacidad económica es el punto de partida de las obligaciones progresivas dentro del sistema tributario, por ser la expresión de la capacidad de pago o capacidad contributiva y responde a principios tan importantes dentro de la concepción del De- recho constitucional tributario como los de solidaridad y equidad; es, además, la forma como se realiza la redistribución del ingreso, siendo la fuerza económica de cada individuo la que con un fin jurídico y no político, como afirma Masbernat (2010), determina o funda la distribución de cargas y obligaciones tributarias.

Y en lo que respecta al impuesto de renta, por ser este el impuesto progresivo por excelencia, la capacidad económica se erige como el aspecto configurador, que le da estructura y le permite establecer las condiciones para el cumplimiento de los deberes formales.

Para este trabajo, no podía dársele otro lugar a la capacidad económica y se erigió en el desarrollo del mismo como el aspecto teórico esencial de dos temas a estudiar: el impuesto de renta en las personas naturales y la demostración cuantitativa de diferencias entre hombres y mujeres en cuanto a factores de relevancia económica para el sistema tributario. Es, además, el vehículo que conecta y relaciona los temas mencionados desde tres aspectos fundamentales que, al ser comunes a ellos, permitieron estructurar la investigación y darle orden. Estos son: el patrimonio, la renta y el consumo, que son los indicadores de la capacidad económica.

Es decir que dentro del sistema tributario actual y con lo que respecta al impuesto de renta como referente, no se ha establecido distinción en cuanto a la capacidad económica por género, lo que no es extraño, ya que dentro de la doctrina y la jurisprudencia (a excepción de la sentencia C-117 -2018) tributaria tampoco. 
En ese punto del planteamiento del problema a investigar, un trabajo realizado por el Dr. Ávila J. (2016) publicado dentro la colección de cuadernillos de trabajo de la DIAN, con un análisis construido partir de las declaraciones de renta del año 2014 de un segmento de contribuyentes no asalariados, se logró demostrar que existe desigualdad de género en aspectos relevantes relacionados con el ya tantas veces mencionado impuesto de renta, como son: el total de declarantes (el $54 \%$ de declarantes son hombres y el $46 \%$, mujeres), patrimonio líquido (hombres poseen el $52,1 \%$ y mujeres, el $47,8 \%$ ), ingresos brutos $(63,56 \%$ obtenido por los hombres, frente al $36,43 \%$ obtenido por las mujeres), entre otros. Con esos datos se puede ya evidenciar que sí existen diferencias entre géneros cuantificables que podrían llevar a concluir que no son semejantes los hombres y las mujeres en cuanto a aspectos de la capacidad económica.

Dado lo anterior, se emprendió el análisis de cada uno de los indicadores de la capacidad económica, con enfoque de género, claro, para desde los incipientes y escasos datos que podían recopilarse, ordenarse y mostrarse buscar corroborar o desestimar la hipótesis primaria planteada con las conclusiones del trabajo mencionado en el párrafo anterior.

En cuanto al patrimonio, se obtuvieron datos de tres aspectos que dan luces acerca de la riqueza y los bienes poseídos por hombres y mujeres en nuestro país, el primero de los cuales es la vivienda propia: en cuanto a vivienda de interés social el Ministerio de Vivienda, Ciudad y territorio publicó que el $70 \%$ de los propietarios son mujeres y tan solo el $30 \%$ de los mismos, son hombres.
Como segundo aspecto se tomaron los depósitos en el sector financiero: las mujeres poseen el 56,1\% de la titularidad de las cuentas de depósito y los hombres el 65,2\%, pero además de este dato se encontró algo muy interesante y es que las mujeres son las mayores usuarias del sistema financiero con un $83,6 \%$ de la población femenina del país en el sistema frente al 76,5\% del género masculino; la diferencia entre las usuarias y la titularidad de las cuantas de depósito se da en el crédito, ya que son ellas son efectivamente las que en tendencia al alza, han venido optando por el endeudamiento principalmente para emprendimiento y nuevos proyectos.

En un tercer momento se tomó el emprendimiento o propiedad de empresa en Colombia: a partir de los análisis de Entrepreneurship Monitor (GEM) en el año 2017, Portafolio en el mismo año y Fenalco pudo ponerse de presente que por cada mujer empresaria hay dos hombres que lo son, siendo dueñas del $56 \%$ de las tiendas de barrio que existen en el país, principalmente. Así como, que ellas reinvierten en un $60 \%$ o $70 \%$ más que sus congéneres masculinos, del dinero obtenido como ganancia en el bienestar de su familia.

Por ende, en cuanto al patrimonio puede concluirse que aunque las mujeres poseen en mayor medida la propiedad de vivienda de interés social en el país (realidad ligada con la cultura tradicional de la titulación de los bienes comunes de las sociedad conyugales o de las sociedades maritales de hecho en cabeza de los hombres únicamente), sus activos en depósitos son inferiores a los de los hombres, su participación en el mercado financiero está principalmente orientada al crédito y son dueñas del $50 \%$ de las empre- 
sas legalmente constituidas en relación con las de los hombres, siendo las tiendas de barrio las unidades de negocio en que más participan ellas.

Con respecto a la renta, entendida como las utilidades conseguidas como resultado de la actividad económica desarrollada, para el caso de este trabajo, el ingreso. Se pusieron en evidencia los siguientes aspectos:

1. De la población económicamente activa y en edad de trabajar son los hombres quienes más se encuentran ocupados con un $75,1 \%$ de participación, frente a una ocupación de 59,6\% de las mujeres, realidad que históricamente va en aumento, según cifras del DANE (2017).

2. De la población económicamente inactiva, el 58,4\% de los hombres se dedicaron a estudiar en comparación con el $59,4 \%$ de las mujeres que se dedicaron a oficios del hogar.

De estos resultados se colige que las mujeres se encuentran más inactivas laboralmente y por tanto poseen menos ingresos propios -con las consecuencias culturales y sociales que esto acarrea- que los hombres; a esta conclusión también llegó la CEPAL (2016), que publicó que para Colombia el 26,4\% de las mujeres mayores de 15 años carecen de ingresos propios y dependen de otras personas perceptoras frente al 10,3\% de los hombres que están en esa condición.

3. Brecha salarial: muchos estudios demuestran que la brecha es real y corresponde a los trabajadores independientes a los siguientes cifras: las personas del género masculino ganan un $35,8 \%$ más que las del género femenino y de los asalariados ganan ellos el $7 \%$ más que aquellas; la causa de eso se puede ver con los resultados de un estudio de la CEPAL (2016) que puso sobre la mesa una realidad: las mujeres trabajan en actividades económicas con menor remuneración y más bajas condiciones de estabilidad y seguridad social y los hombres trabajan en sectores de alta productividad con mejores ingresos y condiciones.

4. Relación entre ingreso y educación: el DANE (2017) demostró que existe relación entre estos dos aspectos, pues las mujeres asalariadas tienen más educación que los hombres asalariados y en cuanto a los independientes son ellas quienes tienen menor grado de capacitación. El estudio concluye que "ser independientes es una opción para personas con bajos niveles educativos".

5. Techo de cristal y Piso pegajoso: estos fenómenos mundialmente conocidos y bastante ilustrados en la literatura social, son limitantes que impiden el desarrollo profesional y por ende económico de las mujeres. Se encuentran fundados en creencias culturales que han estructurado lo femenino y lo masculino, creencias como que hay actividades para mujeres y para hombres; dentro de las que se conciben femeninas se encuentra la de cuidado y el hogar y las de fuerza y poder son para ellos. Las mujeres sentimos que somos responsables de la familia, los hijos y el hogar, y esto puede impedir salir de este, para desempeñar funciones laborales de mayor poder, responsabilidad económica y social, de autoridad o 
simplemente ascender, trabajar más tiempo o educarse.

6. Economía de Cuidado: así se llama a las actividades relacionadas con las labores de administración, mantenimiento del hogar, cuidado de las personas vulnerables (niños, ancianos o enfermos) y el voluntariado social; estas actividades que representan más de la mitad del PIB debido a la gran cantidad de horas empleadas han sido atribuidas culturalmente a las mujeres, quienes las desarrollan en un $78,4 \%$.Y por las que no reciben remuneración económica alguna, o muy baja.

$\mathrm{Si}$ a esto le sumamos que las mujeres invierten diariamente en promedio 7 horas 14 minutos en aquellas actividades, mientras que los hombres 3 horas 25 minutos, vemos como se ven afectados positiva o negativamente el tiempo total de trabajo (13 horas 24 minutos para ellas y 11 horas 16 minutos para ellos) y la remuneración obtenida por el trabajo realizado.

Por último, será el consumo (tendencia a adquirir bienes y servicios para la satisfacción de necesidades) como indicador de la capacidad económica, el que arroje datos en la comparación emprendida:

En primer lugar, debe anotarse que los bienes de la canasta familiar son adquiridos y pagados por mujeres mayoritariamente (2/3) ya que mínimo el 50,8\% de los ingresos de ellas se destinan al hogar, de cada 10 pesos 7 son destinados a compras para el hogar (ENDS - 2015) y por tanto la relación ingreso-gasto se diferencia de acuerdo con el género.
Otro dato preliminar que arrojó luces al respecto surgió de las estadísticas que demuestran que son más pobres los hogares en los que la jefatura la ejerce una mujer (29,7\% de los hogares pobres son mujeres las jefas, frente al $8,7 \%$ de los hogares pobres cuya jefatura es masculina, igualmente de los hogares con pobreza extrema el 25,5\% de los hogares pobres cuentan con jefatura femenina, ante el 6,7\% de los hogares en pobreza extrema es de hombres, según cifras del DANE (2018)).

El aspecto biológico que diferencia a hombres y mujeres, incide directamente sobre las tendencias de consumo desde varias aristas: la adquisición de productos de higiene femenina (tema desarrollado en la sentencia C-117 de 2018), de métodos anticonceptivos, de productos y tratamientos relacionados con la menopausia, todos estos constituyen un gasto mayoritariamente para las mujeres, ya que son ellas las que los requieren y usan; estos gastos relacionados con la fecundidad sobrepasan el $20 \%$ de los ingresos promedios de ellas.

Igual característica presentan los gastos del embarazo, parto y la atención del bebé al nacer, ya que, de acuerdo con cifras del DANE (2017), el 56\% madres en Colombia son $m a-$ dres solteras y responden en forma exclusiva por todos estos productos y servicios, gastos que se verían incrementados si se cuantificaran los gastos de la infancia, adolescencia y juventud de esos niños niñas y adolescentes que solo dependen económicamente de mamá para suplir sus necesidades alimentarias, educativas, recreativas, de salud, etc.

Entonces, con estos datos incipientes y tan difíciles de recaudar se demostró que es 
verídico que se aumentan los gastos en que deben incurrir las mujeres para satisfacer necesidades básicas inherentes a sus condiciones biológicas, gastos que los hombres no hacen, pueslos necesitan.

Si a esta relación gasto necesario-afectación a la capacidad económica, le sumamos otra realidad que repercute en la economía de hombres diferente a la de las mujeres, consistente en la mortalidad adulta, ya que se encuentra demostrado que son ellas quienes viven más tiempo (la razón de mortalidad hombre/mujer es igual a 1,7 hombres por cada mujer) y son además quienes padecen en mayor medida enfermedades críticas debido en parte a las condiciones de autocuidado, podría decirse que las mujeres alcanzan edades más avanzadas y requieren invertir dinero de sus ingresos en tratamientos médicos de alto costo.

Pasando a temas culturales relacionados con el consumo: se inició el estudio con el llamado impuesto rosa que se define como la tasa invisible que incrementa el precio de los productos femeninos entre un 5\% y un 20\% en relación con los de hombres y los mixtos; este incremento es una realidad y así ha quedado evidenciado en productos que van desde los elementos de aseo personal, como los desodorantes, los juguetes, pasando por la ropa y terminando en servicios, como los de peluquería, y ha sido objeto de diferentes análisis, protestas y propuestas a lo largo y ancho del mundo, manifestaciones que pretenden demostrar que este arancel existe, es injusto y que afecta profundamente el presupuesto de mujeres y de paso el del hogar.

Hasta acá el camino fue comparativo y determinante, ya que se recopilaron datos que demuestran varias condiciones que di- ferencian, en cuanto a la capacidad económica a hombres y mujeres, su patrimonio no es homogéneo, sus ingresos sí que distan y las tendencias de consumo los afectan en modo disímil. La conclusión es sencilla: la capacidad económica de hombres y mujeres no es igual y por ende no podrían tratarse -a la luz del sistema tributario- como iguales.

Si la capacidad económica es la base de una mayor equidad en la configuración de sistemas tributarios progresivos, y se encuentra demostrado -como se dijo anteriormente- que entre hombres y mujeres hay factores que hacen que tengan una capacidad económica diferente, debe como consecuencia configurarse dentro del sistema, tratos no homogéneos atendiendo a principios como la equidad vertical y la justicia, por lo menos en lo que respecta al impuesto de renta, que, como ya se dijo, es el impuesto progresivo por excelencia.

Esta conclusión no es nueva, o tal vez sí en Colombia, donde los estudios sobre equidad de género en el sistema tributario son bastante escasos y gozan de poco eco; en otros países es un tema bastante tratado y desarrollado, en nuestro país, este es el primer trabajo que abarca todos los aspectos que se han avizorado y que los cuantifica. En España, por ejemplo, Pazos y Rodríguez afirman que las políticas fiscales y específicamente los sistemas tributarios son herramientas muy útiles para la equidad de género si logran atender la realidad económica de la sociedad y proporcionar incentivos económicos que modifiquen comportamientos culturales de las personas.

Es ese otro aspecto importante, que vale la pena mencionar: el establecimiento de siste- 
mas tributarios está demostrado influyen en los comportamientos de las personas, quienes por "incurrir o aprovechar" un beneficio tributario o mejor, en un trato diferencial que afecta económicamente su impuesto a pagar o su descuento tributario aplicable o le da la posibilidad de incluir en la depuración de su renta unos costos o gastos, cambian conductas culturalmente reprochables, como el atribuir las actividades de la economía de cuidado a las mujeres, o permitir que una mujer se haga responsable sola de su hogar o del embarazo, incluso hasta en contribuir en forma inequitativa con los gastos del hogar privilegiando los gastos individuales y sobrecargando a otro con los gastos familiares.

La concepción económica y cultural de las obligaciones, responsabilidades y compromisos con la familia debe variarse, dirigirse y conseguirse que haya personas sustentadoras/cuidadoras en igualdad, personas que aportan cuidados, atención, dinero y tiempo en similares proporciones y que poseen las mismas condiciones, derechos y "cargas". Y es ahí donde la equidad de género se dará.

Pero volviendo al tema tributario: ¿es posible constitucionalmente hacer estos tratos diferenciados? Con los tratamientos disímiles necesariamente se entraría en una confrontación entre el principio de universalidad del tributo, entendido como la obligación general de los asociados de contribuir a los gastos de la nación (en Colombia corresponden al 59,4\% los ingresos obtenidos por impuestos, tasas y contribuciones) y así garantizar el orden político, económico y social justo, vs. el principio de equidad verticalprogresividadm, que implica un reparto de la carga tributaria de los diferentes sujetos obligados ajustado y limitado a la capacidad contributiva de ellos, es decir, trato igualitario a personas en situaciones idénticas, trato diferente a los diferentes; luego, el cuestionamiento que sigue es ¿cuál de los principios mencionados primaria?

Es necesario para resolver la inquietud acudir al método de determinación de peso de principios, conocido con el nombre de Ponderación de principios. Este método seguido por la Corte Constitucional en múltiples sentencias, más el complemento dado por la metodología del Análisis Económico del Derecho (Medellín, 2013) permite, mediante el desarrollo de ecuaciones (cuantificación objetiva), obtener un resultado numérico sobre la prevalencia y conveniencia de la aplicación de tal o cual principio.

Luego de formular los pesos del principio constitucional de la universalidad-generalidad vs. el de la progresividad-equidad vertical, se concluyó que tiene mayor peso el segundo principio en relación con el primero, con una diferencia mínima que puede no justificar la implementación de tratos tributarios diferenciados.

$\mathrm{Al}$ realizar el ejercicio del AED en cuanto a los costos de producción de un principio sobre el otro y de los efectos económicos a largo plazo con respecto al precedente, se produjo un aumento en la distancia de prevalencia del principio de equidad vertical sobre el de generalidad.

Y unidas las fórmulas del peso con las del AED se concluyó que la incorporación de las dos variables del AED aumentó la distancia del peso entre los principios, aumentando también las posibilidades de protección del principio de equidad vertical sobre el de 
la universalidad, ya que las implicaciones económicas positivas en los ingresos de la nación de la implementación de medidas de diferenciación por género, con base en la capacidad económica, se dan a mediano y largo plazo, y principalmente al reflejarse un cambio cultural que mejoraría la calidad de vida de los colombianos, la equidad en las relaciones familiares y sociales y la consecuente dinamización del ciclo económico.

Dado lo anterior, se emprendió el análisis de cada uno de los indicadores de la capacidad económica, con enfoque de género, claro, para desde los incipientes y escasos datos que podían recopilarse, ordenarse y mostrarse, buscar corroborar o desestimar la conclusión primaria a la que se había llegado con el trabajo en el párrafo anterior mencionado.

En cuanto al patrimonio, se obtuvieron datos de tres aspectos que dan luces a cerca de la riqueza y los bienes poseídos por hombres y mujeres en nuestro país, el primero de los cuales es la vivienda propia: en cuanto a vivienda de interés social el Ministerio de Vivienda, Ciudad y territorio publicó que el $70 \%$ de los propietarios son mujeres y tan solo el $30 \%$ de los mismos, hombres. Como segundo aspecto se tomaron los depósitos en el sector financiero: las mujeres poseen el $56,1 \%$ de la titularidad de las cuentas de depósito y los hombres, el $65,2 \%$, pero además de este dato se encontró algo muy interesante $\mathrm{y}$ es que las mujeres son las mayores usuarias del sistema financiero con un $83,6 \%$ de la población femenina del país en el sistema frente al 76,5\% del género masculino; la diferencia entre las usuarias y la titularidad de las cuentas de depósito se da en el crédito, ya que ellas son efectivamente las que con tendencia al alza han venido optando por el endeudamiento principalmente para emprendimiento y nuevos proyectos.

En un tercer momento se tomó el emprendimiento o propiedad de empresa en Colombia: a partir de los análisis de Entrepreneurship Monitor (GEM) en el 2017, Portafolio en el mismo año y Fenalco pudo ponerse de presente que por cada mujer empresaria hay dos hombres que lo son, siendo dueñas del $56 \%$ de las tiendas de barrio que existen en el país, principalmente. Y que a pesar de que ellas reinvierten en un $60 \%$ o $70 \%$ más del dinero obtenido como ganancia en el bienestar de su familia.

Por ende, en cuanto al patrimonio puede concluirse que aunque las mujeres poseen en mayor medida la propiedad de vivienda de interés social en el país (realidad ligada con la cultura tradicional de la titulación de los bienes comunes de las sociedad conyugales o de las sociedades maritales de hecho en cabeza de los hombres únicamente), sus activos en depósitos son inferiores a los de los hombres, su participación en el mercado financiero está principalmente orientada al crédito y son dueñas del $50 \%$ de las empresas legalmente constituidas en relación con las de los hombres, siendo las tiendas de barrio las unidades de negocio en que más participan ellas.

Con respecto a la renta, entendida como las utilidades conseguidas como resultado de la actividad económica desarrollada, para el caso de este trabajo, el ingreso. Se pusieron en evidencia los siguientes aspectos:

1. La mayor cantidad de población económicamente activa y en edad de tra- 
bajar son los hombres quienes más se encuentran ocupados con un $75,1 \%$ de participación, frente a una ocupación de $59,6 \%$ de las mujeres, realidad que históricamente va en aumento, según cifras del DANE (2017).

2. De la población económicamente inactiva el 58,4\% de los hombres se dedicaron a estudiar en comparación con el $59,4 \%$ de las mujeres que se dedicaron a oficios del hogar.

De estos resultados se colige que las mujeres se encuentran más inactivas laboralmente y por tanto poseen menos ingresos propios -con las consecuencias culturales y sociales que esto acarrea- que los hombres; a esta conclusión también llegó la CEPAL (2016), que publicó que para Colombia el 26,4\% de las mujeres mayores de 15 años carecen de ingresos propios y dependen de otras personas perceptoras frente al $10,3 \%$ de los hombres que están en esa condición.

Brecha salarial: muchos estudios demuestran que es real la brecha: dada en cifras de los trabajadores independientes, las personas del género masculino ganan un 35,8\% más que las del género femenino y de los asalariados ganan ellos el $7 \%$ más que aquellas; la causa de eso se puede ver con los resultados de un estudio de la CEPAL (2016) que puso sobre la mesa una realidad: las mujeres trabajan en actividades económicas con menor remuneración y más bajas condiciones de estabilidad y seguridad social y los hombres trabajan en sectores de alta productividad con mejores ingresos y condiciones.

Relación entre ingreso y educación: el DANE (2017) demostró que existe relación entre estos dos aspectos: las mujeres asala- riadas tienen más educación que los hombres asalariados y en cuanto a los independientes son ellas quienes tienen menor grado de capacitación; el estudio concluye que "ser independientes es una opción para personas con bajos niveles educativos".

Techo de cristal y Piso pegajoso: estos fenómenos mundialmente conocidos y bastante ilustrados en la literatura social, son limitantes que impiden el desarrollo profesional y por ende económico de las mujeres, se encuentran dados por creencias culturales que han estructurado lo femenino y lo masculino, con creencias como: hay actividades para mujeres y hombres, dentro de las cuales se encuentra la de cuidado y el hogar para ellas y las de fuerza y poder para ellos. Las mujeres se sienten responsables de la familia, los hijos y el hogar, lo que les impide salir del hogar y desempeñar funciones laborales de mayor poder, responsabilidad económica y social, de autoridad o simplemente ascender, trabajar más tiempo o educarse.

Economía de cuidado: así se llama a las actividades relacionadas con las labores de administración, mantenimiento del hogar, cuidado de las personas vulnerables (niños, ancianos o enfermos) y el voluntariado social, esta actividad que representa más de la mitad del PIB debido a la gran cantidad de horas empleadas han sido atribuidas culturalmente a las mujeres, quienes las desarrollan en un $78,4 \%$. Y por las que no reciben remuneración económica alguna, o muy baja.

$\mathrm{Si}$ a esto le sumamos que las mujeres invierten diariamente en promedio 7 horas 14 minutos en aquellas actividades mientras que los hombres 3 horas 25 minutos, vemos como se ven afectados positiva o negativa- 
mente el tiempo total de trabajo (13 horas 24 minutos para ellas y 11 horas 16 minutos para ellos) y la remuneración obtenida por el trabajo realizado.

Por último, sería el consumo (tendencia a adquirir bienes y servicios para la satisfacción de necesidades) como indicador de la capacidad económica el que arroje datos en la comparación emprendida:

En primer lugar, debe anotarse que los bienes de la canasta familiar son adquiridos y pagados por mujeres mayoritariamente $(2 / 3)$ ya que mínimo el 50,8\% de los ingresos de ellas se destinan al hogar, de cada 10 pesos 7 son destinados a compras para el hogar (ENDS - 2015) por tanto la relación ingresogasto se diferencia de acuerdo con el género.

Otro dato preliminar que arrojó luces al respecto surgió de las estadísticas que demuestran que son más pobres los hogares en los que la jefatura la ejerce una mujer $(29,7 \%$ de los hogares pobres son mujeres las jefas y el $8,7 \%$ de los hogares con pobreza extrema frente al $25,5 \%$ de los hogares pobres cuentan con jefe hombre y el $6,7 \%$ de los hogares en pobreza extrema, según cifras del DANE (2018)).

Otros aspectos relacionados con el consumo que aportan luces al tema fueron el biológico: el uso de productos de higiene femenina (tema desarrollado en la sentencia C-117 de 2018), de métodos anticonceptivos, de productos y tratamientos relacionados con la menopausia, constituyen un gasto mayoritariamente para las mujeres, ya que son ellas quienes los requieren y usan en la mayoría de los casos; estos gastos relacio- nados con la fecundidad de ellas sobrepasan el $20 \%$ de los ingresos promedios de ellas.

Con los pocos datos que existen sobre los gastos del embarazo, parto y la atención del bebé al nacer que, de acuerdo con cifras DANE (2017), atienden las mujeres mayoritariamente por ser el $56 \%$ madres solteras, se demostró que se aumentan los gastos que por la biología del ser humano deben acarrear las mujeres.

Todo esto llevó a otra realidad que repercute en la capacidad económica de hombres diferente de mujeres y es que en lo que respecta a la mortalidad adulta ya que "la razón de mortalidad hombre/mujer es igual a 1,7 hombres por cada mujer". Son ellas quienes viven más tiempo y quienes se ven afectadas en mayor medida por enfermedades críticas debido en parte a las condiciones de autocuidado en que viven; entonces, alcanzan las mujeres edades más avanzadas y requieren invertir dinero de sus ingresos en tratamientos médicos de alto costo.

Pasando a temas culturales relacionados con el consumo: se inició el estudio con el llamado impuesto rosa que se define como la tasa invisible que incrementa el precio de los productos femeninos entre un $5 \%$ a un $20 \%$ en relación con los de los hombres y los mixtos. Este incremento es una realidad y así ha quedado evidenciado en productos que van desde los elementos de aseo personal, como los desodorantes, los juguetes, pasando por la ropa y terminando en servicios, como los de la peluquería, y ha sido objeto de diferentes análisis, protestas y propuestas a lo largo $\mathrm{y}$ ancho del mundo que pretenden demostrar que existe, que es injusto y que afecta pro- 
fundamente el presupuesto de mujeres $\mathrm{y}$, de paso, del hogar.

Hasta acá el camino fue comparativo: pudo establecerse que existen vastas condiciones que diferencian en cuanto a la capacidad económica a hombres y mujeres, su patrimonio no es homogéneo, sus ingresos sí que distan y las tendencias de consumo los afectan en modos desigual. La conclusión es sencilla: "la capacidad económica de hombres y mujeres no es igual por ende no podrían tratarse -a la luz del sistema tributario- como iguales".

Si la capacidad económica es la base para una mayor equidad al crear parámetros para la configuración se sistemas progresivos, debe darse un trato no homogéneo atendiendo a principios como la equidad vertical y la justicia a las personas naturales, por lo menos en lo que respecta al impuesto de renta, que, como ya se dijo, es el impuesto progresivo por excelencia.

Esta conclusión no es nueva, o tal vez sí en Colombia, donde los estudios sobre equidad de género en el sistema tributario son bastante escasos y gozan de poco eco; en otros países es un tema bastante tratado y desarrollado, y en nuestro país, este es el primer trabajo que abarca todos los aspectos que se han avizorado y que los cuantifica. En España, por ejemplo, Pazos y Rodríguez llegan a una conclusión similar a la acá planteada al decir que las políticas fiscales y específicamente los sistemas tributarios son herramientas muy útiles para la equidad de género, si logran atender a la realidad económica de la sociedad y proporcionar incentivos económicos que modifiquen comportamientos culturales de las personas.
Es ese otro aspecto importante, que vale la pena mencionar: el establecimiento de sistemas tributarios - está demostrado- influyen en los comportamientos de las personas, que por "incurrir o aprovechar" un beneficio tributario o, mejor, un trato diferencial que afecta económicamente su impuesto a pagar o su descuento tributario aplicable o le da la posibilidad de incluir en la depuración de su renta unos costos o gastos, cambia conductas culturalmente reprochables, como el atribuir las actividades de la economía de cuidado a las mujeres, o permitir que una mujer se haga responsable sola de su hogar o su embarazo o consumir en tan poca medida con los gastos del hogar privilegiando los gastos en ellos.

Está claro que la concepción familiar debe cambiar, con personas sustentadoras/cuidadoras en igualdad, dos personas que aportan en iguales condiciones y poseen las mismas condiciones y responsabilidades. $\mathrm{Y}$ es ahí donde la equidad de género se dará.

¿Pero es posible constitucionalmente hacer estos tratos diferenciados? Es decir, en una confrontación entre el principio de universalidad del tributo, entendido como la obligación general de los asociados de contribuir a los gastos de la nación (que en Colombia corresponden al 59,4\% de los ingresos obtenidos por impuestos, tasas y contribuciones) y así garantizar el orden político, económico y social justo... vs. el principio de equidad vertical progresividad, que implica un reparto de la carga tributaria de los diferentes sujetos obligados ajustado y limitado a la capacidad contributiva de ellos, es decir, trato igualitario a personas en situaciones idénticas, taro diferente a los diferentes, ¿cuál de los principios primaría? 
Es necesario, para resolver el cuestionamiento, acudir a un método de determinación de peso de principios, conocido con el nombre de ponderación de principios. Este método, seguido por la Corte Constitucional en múltiples sentencias, más el complemento dado por la metodología del Análisis Económico del Derecho (Medellín, 2013), permite, mediante el desarrollo de ecuaciones (Cuantificación objetiva), obtener un resultado numérico sobre la prevalencia y conveniencia de la aplicación de tal o cual principio. Luego de formular los pesos de la universalidad-generalidad y de la progresividad-equidad vertical se concluyó que tiene mayor peso el segundo principio en relación con el primero, con una diferencia mínima que puede no justificar la implementación de tratos tributarios diferenciados.

Al realizar el ejercicio del AED en cuanto a los costos de producción de un principio sobre el otro y de los efectos económicos a largo plazo con respecto al precedente, se dio un aumento en la distancia de prevalencia del principio de equidad vertical sobre el de generalidad.

Y unidas las fórmulas del peso con las del AED, se concluyó que la incorporación de las dos variables del AED aumentó la distancia del peso entre los principios, incrementando las posibilidades de protección del principio de equidad vertical sobre el de la universalidad, aunque las implicaciones económicas positivas en los ingresos de la nación de la implementación de medidas de protección se den a mediano y largo plazo al reflejarse un cambio cultural que mejoraría la calidad de vida de los colombianos, la equidad en las relaciones familiares y sociales y la consecuente dinamización del ciclo económico.

\section{Referencias}

Arango, C.A.; Suárez, N. y Garrido, S.H. (2017). Cómo pagan los colombianos y Por qué. Borradores de Economía. Bogotá, Colombia. Banco de la República. Borrador No. 991 (p. 11).

Arias, L.; Mansilla, F. y Rincón, L. (2017). Impuestos y Desigualdad de género en Colombia. Supuestos revista económica. Volumen 4 año 201.

Ávila, J. y Cruz, A. (2006). La progresividad del sistema tributario colombiano del orden nacional: Un análisis para el IVA y el impuesto sobre la renta. Cuaderno de trabajo, documento Web 014, DIAN, Bogotá, Colombia.

Ávila, J. (2016). Diferencias de género en la riqueza, ingresos y renta de personas naturales en Colombia. Bogotá, Colombia. Dirección de Impuestos y Aduanas Nacionales.

Campuzano, J. y Palacios, B. (2009). "El impacto de las políticas impositivas en el Ecuador: un análisis desde la perspectiva de género". SRIUnifem. Guayaquil.

Corte Constitucional de Colombia. Sentencia C-445 de 1995. (M.P.Alejandro Martínez Caballero (octubre 4 de 1995).

Corte Constitucional de Colombia. Sentencia C-776 de 2003, M.P. Manuel José Cepeda Espinosa.

Corte Constitucional de Colombia. Sentencia C-913 de 2011. (M.P. Gabriel Eduardo Mendoza Martelo (diciembre 6 de 2011).

Corte Constitucional de Colombia. Sentencia C-100 de 2014. (M.P. María Victoria Calle Correa (26 de febrero de 2014).

Corte Constitucional de Colombia. Sentencia C-209 de 2016. (M.P. Jorge Iván Palacio Palacio (27 de abril de 2016).

DANE (2018). Comunicado de prensa Informes especiales de mercado laboral Trimestre móvil mayo-julio 2018. Bogotá Colombia. (p. 5)

Dinero (2013). Mujeres, las grandes compradoras, Tendencias, abril 16

Entrepreneurship Monitor - GEM (2017). GEM 2016 / 2017 global report. Reports

Gherardi, N. y Rodríguez, C. (2008). Los impuestos como herramienta para la equidad de género: el caso del impuesto a las ganancias sobre personas físicas 
en Argentina, Documento de trabajo No. 67, CIEPP y Ela. Pág. 2 y 4

Gómez, E. (2008), "La valoración del trabajo no remunerado: una estrategia clave para la política de igualdad de género", en Organización Panamericana de la Salud, La economía invisible y las desigualdades de género. La importancia de medir y valorar el trabajo no remunerado, Washington, E.U. Capítulo I.

La Opinión (2017). ¿Cuánto cuesta nacer en Cúcuta?, 10 de diciembre

Masbernat, P. (2010). Artículos de doctrina, el principio de capacidad económica como principio jurídico material de la tributación: su elaboración doctrinal y jurisprudencial en España. Revista lus et Praxis, Año 16, No. 1, (pp. $303-332$ ).

Medellín, A. (2013). La ponderación y el análisis Económico del Derecho, Universidad Externado de Colombia. Bogotá, Colombia. Pág. 36 a 40

Medina M.A., (2017). La lucha contra el impuesto a toallas y tampones, en El Espectador sección economía. 14 de junio

Minsalud (2015). Encuesta Nacional de Demografía y Salud. ENDS Colombia 2015. Bogotá Colombia.

Moreno, N. y Plazas, C. (2015). Política Fiscal y Género: que no se descargue la crisis sobre las mujeres, 2015, Red por la justicia Tributaria en Colombia. Bogotá, Colombia. En www. Justicia Tributaria.co.

ONU Mujeres (2013). Hechos y cifras: Empoderamiento económico. Empoderamiento Económico, Nueva York, USA.

Pazos, M. y Rodríguez, M. (2010). Fiscalidad y equidad de género. Documento de trabajo No. 43. Fundación Carolina, CeALCI, Madrid, España (pp. 2 y 6).
Piza, J. R., (2011). Capacidad económica como principio del sistema tributario. Revista de Derecho Fiscal, (1). (p.p. 62 al 76). Recuperado a partir de https://revistas.uexternado.edu.co/index.php/fiscal/ article/view/2668

Portafolio (2017). Emprendimiento femenino en Colombia creció $25 \%$ en el último año, en sección Emprendimiento, noviembre 30.

Portafolio (2018). ¿En qué gastan el dinero las mujeres?, en sección Economía, marzo 8.

Romero C.; Grass, Y. y García, X. (2013). Principios constitucionales que rigen el sistema tributario. Derecho y Políticas públicas, DIXI, Volumen 15 Número 17, At. 67.

Sarmiento, L. (2018). Colombia. Presupuesto General de la nación, Desde abajo, Suplemento Educación y Economía Nº 7 , Edición N. . 243, Febrero 20 - Marzo 20 de 2018

Tenjo, J. y Bernat, L. (2017). Diferencias por género en el mercado laboral colombiano: mitos y realidades. Bogotá, Colombia. Departamento de Economía, Universidad Jorge Tadeo Lozano.

Universidad de los Andes (2017). Encuesta Longitudinal Colombiana de la Universidad de los Andes (ELCA). Colombia en movimiento 2010 - 2013 - 2016, Economía.

Fecha de recepción: 13 de marzo de 2019

Fecha de aprobación par 1: 22 de mayo de 2019

Fecha de aprobación par 2: 12 de agosto de 2019 